OPEN ACCESS

Edited by:

Joerg Graf,

University of Connecticut, USA

Reviewed by:

Alessandra Salvioli,

University of Turin, Italy

Ulisses Nunes Da Rocha,

VU University Amsterdam,

Netherlands

*Correspondence:

A. Elizabeth Arnold

arnold@ag.arizona.edu

Specialty section: This article was submitted to

Microbial Symbioses,

a section of the journal

Frontiers in Microbiology

Received: 06 November 2016

Accepted: 20 February 2017

Published: 14 March 2017

Citation:

Shaffer JP, U'Ren JM, Gallery RE, Baltrus DA and Arnold AE (2017) An

Endohyphal Bacterium (Chitinophaga, Bacteroidetes) Alters Carbon Source

Use by Fusarium keratoplasticum ( $F$.

solani Species Complex, Nectriaceae).

Front. Microbiol. 8:350.

doi: 10.3389/fmicb.2017.00350

\section{An Endohyphal Bacterium (Chitinophaga, Bacteroidetes) Alters Carbon Source Use by Fusarium keratoplasticum (F. solani Species Complex, Nectriaceae)}

\author{
Justin P. Shaffer' ${ }^{1}$, Jana M. U'Ren ${ }^{1,2}$, Rachel E. Gallery ${ }^{3,4}$, David A. Baltrus $^{1}$ and \\ A. Elizabeth Arnold ${ }^{1,4 *}$
}

${ }^{1}$ School of Plant Sciences, University of Arizona, Tucson, AZ, USA, ${ }^{2}$ Department of Agricultural and Biosystems Engineering, University of Arizona, Tucson, AZ, USA, ${ }^{3}$ School of Natural Resources and the Environment, University of Arizona, Tucson, AZ, USA, ${ }^{4}$ Department of Ecology and Evolutionary Biology, University of Arizona, Tucson, AZ, USA

Bacterial endosymbionts occur in diverse fungi, including members of many lineages of Ascomycota that inhabit living plants. These endosymbiotic bacteria (endohyphal bacteria, EHB) often can be removed from living fungi by antibiotic treatment, providing an opportunity to assess their effects on functional traits of their fungal hosts. We examined the effects of an endohyphal bacterium (Chitinophaga sp., Bacteroidetes) on substrate use by its host, a seed-associated strain of the fungus Fusarium keratoplasticum, by comparing growth between naturally infected and cured fungal strains across 95 carbon sources with a Biolog ${ }^{\circledR}$ phenotypic microarray. Across the majority of substrates $(62 \%)$, the strain harboring the bacterium significantly outperformed the cured strain as measured by respiration and hyphal density. These substrates included many that are important for plant- and seed-fungus interactions, such as D-trehalose, myoinositol, and sucrose, highlighting the potential influence of EHB on the breadth and efficiency of substrate use by an important Fusarium species. Cases in which the cured strain outperformed the strain harboring the bacterium were observed in only $5 \%$ of substrates. We propose that additive or synergistic substrate use by the fungusbacterium pair enhances fungal growth in this association. More generally, alteration of the breadth or efficiency of substrate use by dispensable EHB may change fungal niches in short timeframes, potentially shaping fungal ecology and the outcomes of fungal-host interactions.

Keywords: endobacteria, fusaria, Gram-negative, phenotypic microarray, substrate use, symbiosis

\section{INTRODUCTION}

Plant-fungus interactions shape plant health and productivity in all terrestrial ecosystems (Heilmann-Clausen and Boddy, 2008; Kivlin et al., 2011; Tedersoo et al., 2014; Davison et al., 2015). Pathogens can negatively influence photosynthesis, nutrient- and water uptake and transport, structural integrity, reproduction, and seed germination of their hosts (Blanchette, 1991; Agrios, 1997; Gallery et al., 2007; Grimmer et al., 2012; Oliva et al., 2014). In turn, mycorrhizal fungi 
and some endophytes may enhance nutrient uptake and growth, alter plant water relations, or deter antagonistic microbes or herbivores (Arnold et al., 2003; Waller et al., 2005; Arnold and Engelbrecht, 2007; Busby et al., 2015; Estrada et al., 2015; van der Heijden et al., 2015).

Outcomes of such interactions are influenced by genetic and environmental factors (Schafer and Kotanen, 2003; Gallery et al., 2010; see Agrios, 1997; Jones and Dangl, 2006), but also can be shaped by additional microorganisms that alter fungal phenotypes (Frey-Klett et al., 2007; Márquez et al., 2007). Such microbes may occur on the exterior surfaces or interior of fungal cells, where they can alter sporulation, substrate use, metabolite production, and other features relevant to fungal interactions with plants (Partida-Martínez and Hertweck, 2005; Salvioli et al., 2010; Hoffman et al., 2013; Spraker et al., 2016). In particular, many plant-associated fungi harbor endosymbiotic bacteria (hereafter, endohyphal bacteria, EHB) that can affect host function and subsequent plant-fungus interactions (PartidaMartínez and Hertweck, 2005; Hoffman et al., 2013; Salvioli et al., 2016). EHB are known among diverse fungi (Hoffman and Arnold, 2010; Desirò et al., 2015; Shaffer et al., 2016), but only a few have been developed as model systems in which their effects have been observed.

The majority of studies to date focus on EHB in diverse rootassociated and soilborne fungi, particularly Mucoromycotina, Mortierellomycotina, and Glomeromycotina (Bianciotto et al., 2003; Bertaux et al., 2005; Partida-Martínez et al., 2007b; Sharma et al., 2008; Sato et al., 2010; Desirò et al., 2015). Many of these EHB influence the phenotype of their fungal hosts. For example, the bacterium Burkholderia rhizoxinica produces a virulence factor that enables its host fungus Rhizopus microsporus (Mucoromycotina) to cause disease on rice (Partida-Martínez and Hertweck, 2005; Partida-Martínez et al., 2007b). When the bacterium is removed, the fungus is no longer pathogenic and loses the ability to reproduce asexually (Partida-Martínez and Hertweck, 2005; Partida-Martínez et al., 2007a). The bacterium Candidatus Glomeribacter gigasporarum increases responsiveness to strigolactones exuded by roots, enhancing hyphal elongation and branching relevant to mycorrhizal establishment by Gigaspora margarita (Gigasporaceae, Glomeromycotina) (Bianciotto et al., 1996, 2003, 2004; Lumini et al., 2007; Anca et al., 2009).

EHB also occur in Basidiomycota, with case studies beginning to highlight the functional aspects of their associations in rhizosphere and phyllosphere fungi (Bertaux et al., 2005; Izumi et al., 2005; Sharma et al., 2008; Ruiz-Herrera et al., 2015). For example, Rhizobium radiobacter (syn. Agrobacterium tumefaciens), like its host, Piriformospora indica (Sebacinales), can promote growth and induce disease resistance in barley (Sharma et al., 2008). Similarly, a Bacillus sp. fixes and makes available atmospheric nitrogen within cells of Ustilago maydis (Ustilaginomycotina; Ruiz-Herrera et al., 2015).

EHB recently have been documented in diverse Ascomycota, including members of multiple classes (Pezizomycetes, Eurotiomycetes, Dothideomycetes, and Sordariomycetes) and multiple functional groups (Barbieri et al., 2000; Hoffman and
Arnold, 2010; Shaffer et al., 2016). They are widespread in foliar endophytes and in soilborne Ascomycota (e.g., those that interact with seeds; Hoffman and Arnold, 2010; Shaffer et al., 2016). To date their functional significance has been assessed in detail in only one study system: the foliar endophyte Pestalotiopsis sp. (Amphisphaeriaceae, Xylariales, Sordariomycetes) and its EHB, Luteibacter sp. (Xanthomonadaceae, Gammaproteobacteria; Hoffman et al., 2013; Arendt, 2015). More generally, studies of EHB in the Ascomycota and other fungi have focused primarily on Proteobacteria, Firmicutes, and Mollicutes (e.g., Desirò et al., 2015; see also Baltrus et al., 2016), leaving gaps with regard to the potential for symbiotic modulation of fungal phenotypes by members of other bacterial lineages.

Here, we use a phenotypic microarray (PM) to explore the influence of an $\mathrm{EHB}$ on its fungal host under laboratory conditions. Approaches to evaluate phenotypic effects of EHB on host fungi range from predictive analyses based on genomics and related tools to assays that use infected and cured strains of the same fungus (Anca et al., 2009; Ghignone et al., 2012; Hoffman et al., 2013). The advantage of our approach is that it allows quantification of respiration and growth on 95 substrates simultaneously, providing withinexperiment controls and comparisons that are not subject to variation introduced in a lower-throughput framework (Atanasova et al., 2010; Druzhinina et al., 2010; Blumenstein et al., 2015a,b). PMs have been used in diverse studies involving bacteria (reviewed in Bochner, 2008), and since their development have been extended to work with fungi, including yeasts and filamentous strains (reviewed in Bochner, 2003; Druzhinina et al., 2006; Atanasova and Druzhinina, 2010; Pfliegler et al., 2014). To our knowledge, PMs have not been used previously to explore interactions among microbes or more specifically, the effects of bacterial endosymbionts on fungal phenotypes.

In this study we focus on a lineage of bacteria that has not yet been evaluated for phenotypic modulation of fungi: the Bacteroidetes, a diverse clade of Gram-negative, nonendospore forming bacteria that are known from soils and from diverse symbiotic associations (Krieg et al., 2010; Thomas et al., 2011). Specifically we examine the effects of a strain of Chitinophaga sp. (Bacteroidetes) on substrate use by its host fungus, a strain of Fusarium keratoplasticum (F. solani species complex, FSSC, sensu Short et al., 2013). The fungal strain was originally isolated from the interior of a seed of a tropical tree that was retrieved from soil in a tropical forest. Subcultures of the strain consistently harbor Chitinophaga sp., and preliminary analyses indicated that this bacterium can be removed by antibiotic treatment. Here we show that this endohyphal Chitinophaga alters substrate use and substrate-specific growth by its host fungus. Our results highlight the importance of EHB with regard to shaping fungal phenotypes relevant to plant-fungus interactions and demonstrate the capacity of a focal member of the Bacteroidetes to alter the functional traits of a fungal species that includes medically and ecologically important strains. 


\section{MATERIALS AND METHODS}

As part of a previous study (Sarmiento et al., 2015; Zalamea et al., 2015), a fungus was isolated from a seed of Cecropia insignis (Urticaceae) that had been buried for 1 month in the soil in the tropical forest understory at Barro Colorado Island, Panama $\left(9^{\circ} 10^{\prime} \mathrm{N}, 79^{\circ} 51^{\prime} \mathrm{W} ; 86\right.$ m.a.s.l.; for a site description see Leigh, 1999). The seed was retrieved from the soil, washed in water, and surface-sterilized by sequential immersion in $95 \%$ ethanol (10 s), diluted chlorine bleach $(0.525 \% \mathrm{NaClO} ; 2 \mathrm{~min})$, and $70 \%$ ethanol (2 min) (Arnold and Lutzoni, 2007). The seed was cut in half and allowed to surface-dry under sterile conditions. One half of the seed was placed on $2 \%$ malt extract agar (MEA) following Gallery et al. (2007). Fungal isolate PS0362A, containing its bacterial symbiont, grew from the interior of the seed. PS0362A was deposited as a living voucher at the Robert L. Gilbertson Mycological Herbarium, University of Arizona.

Phylogenetic analyses based on three loci identified PS0362A as F. keratoplasticum, a member of the Fusarium solani species complex (FSSC) (Nectriaceae, Hypocreales, Sordariomycetes, Ascomycota; Shaffer et al., 2016). Its bacterial symbiont was observed during screening and was identified by phylogenetic analysis of the $16 S$ ribosomal RNA (rRNA) gene as Chitinophaga sp. PS-EHB01 (Bacteroidetes) (Shaffer et al., 2016). We have refined the placement of Chitinophaga sp. PS-EHB01 within the Chitinophagaceae by focusing taxon sampling and inferring a new $16 S$ phylogeny, confirming its taxonomic identity (see Supplementary Materials and Methods).

\section{Preparation of Axenic Fungal Culture}

Fusarium keratoplasticum PS0362A was naturally infected by Chitinophaga sp. PS-EHB01. We prepared an axenic strain of the fungus by subculturing hyphae under sterile conditions on 2\% MEA amended with four antibiotics: ampicillin (100 $\mu \mathrm{g} / \mathrm{mL})$, kanamycin $(50 \mu \mathrm{g} / \mathrm{mL})$, tetracycline $(10 \mu \mathrm{g} / \mathrm{mL})$, and ciprofloxacin (40 $\mu \mathrm{g} / \mathrm{mL}$; see Hoffman and Arnold, 2010; Hoffman et al., 2013; Arendt et al., 2016). We refer to clones of the naturally infected fungus as the $\mathrm{EHB}+$ strain, and those of the axenic fungus as the $\mathrm{EHB}$ - strain.

We confirmed the presence or absence of Chitinophaga sp. PSEHB01 in F. keratoplasticum PS0362A through light microscopy, molecular analysis, and fluorescence microscopy. We first ruled out extrahyphal bacteria (i.e., contaminants in the medium or microbes on hyphal surfaces; see Supplementary Figure 1) by examining five samples of hyphae per culture at $400 \mathrm{X}$ and $1,000 \mathrm{X}$ on a Leica DM400B compound microscope. We did not observe extrahyphal bacteria in any cultures of the $\mathrm{EHB}+$ or $\mathrm{EHB}-$ strains used here.

We extracted total genomic DNA from fresh mycelia of $\mathrm{EHB}+$ and $\mathrm{EHB}-$ strains using the REDExtract-N-Amp Plant Kit (Sigma-Aldrich, St. Louis, MO, USA) following a modified protocol (see U'Ren, 2016; U'Ren et al., 2016). We prepared five separate DNA extractions per strain type. We used the polymerase chain reaction (PCR) to amplify a ca. 1,400 base pair (bp) segment of the $16 \mathrm{~S}$ rRNA gene (forward primer 27F, reverse primer 1492R; $10 \mu \mathrm{M}$; Lane, 1991) with PCR cycling parameters following Hoffman and Arnold (2010) (3 min at $94^{\circ} \mathrm{C}$, 40 cycles of $30 \mathrm{~s}$ at $94^{\circ} \mathrm{C}, 30 \mathrm{~s}$ at $55^{\circ} \mathrm{C}$, and $2 \mathrm{~min}$ at $72^{\circ} \mathrm{C}$, followed by 10 $\min$ at $72^{\circ} \mathrm{C}$ ). For each reaction we used $10 \mu \mathrm{L}$ of PCR Ready Mix, $0.8 \mu \mathrm{L}$ of each primer, $4.4 \mu \mathrm{L}$ of molecular grade water, and $4 \mu \mathrm{L}$ of DNA template. We used molecular grade water instead of template in negative controls. Negative controls never resulted in visible, positive PCR products. Positive controls consisted of a bacterial strain that was amplified consistently with these primers. Positive controls yielded amplification as expected in every PCR.

Positive PCR products were cleaned by adding $1 \mu \mathrm{L}$ ExoSAPIT (Affymetrix, Santa Clara, CA, USA) to each of the remaining products. Reactions were incubated on a thermal cycler at $37^{\circ} \mathrm{C}$ for $60 \mathrm{~min}$, and then at $80^{\circ} \mathrm{C}$ for $15 \mathrm{~min}$ to deactivate enzymes. Cleaned PCR products were diluted 1:1 with molecular grade water and sequenced bidirectionally on an AB3730XL (Applied Biosystems, Foster City, CA, USA) using PCR primers (5 $\mu \mathrm{M})$ at the University of Arizona Genomics Core.

An assembly pipeline consisting of phred and phrap (Ewing and Green, 1998; Ewing et al., 1998) driven by Chromaseq (Maddison and Maddison, 2005) in Mesquite v.2.75 (Maddison and Maddison, 2009) was used to call bases and assemble bidirectional reads into contigs. Base calls were verified by manual inspection of all chromatograms in Sequencher v.5.1 (Gene Codes Corp., Ann Arbor, MI, USA).

We consistently found Chitinophaga sp. PS-EHB01 in cultures of the EHB+ strain of F. keratoplasticum PS0362A. No other bacteria were observed in that strain. Chitinophaga sp. PSEHB01 was not detected in cultures of the EHB - strain of F. keratoplasticum PS0362A, and we observed no other bacteria in clones of that strain.

To confirm that Chitinophaga sp. PS-EHB01 was viable and that it occurred within viable hyphae, we examined living hyphae by microscopy with the Live/Dead BacLight Bacterial Viability Kit (Invitrogen, Carlsbad, CA, USA) following Hoffman and Arnold (2010). The kit provides a two-color fluorescence assay of bacterial viability that uses two dyes: SYTO 9, a green-fluorescent nucleic acid stain that labels all cells, and propidium iodide, a red-fluorescent nucleic acid stain that labels only those cells with damaged or otherwise compromised cell membranes (see manufacturer's instructions).

We prepared fungal cultures for Live/Dead visualization by removing a small piece of mycelium $\left(\leq 2-\mathrm{mm}^{2}\right)$ from the growing edge of a single colony growing on $2 \%$ MEA. Fragments were aseptically transferred to glass slides containing $20 \mu \mathrm{L}$ of 1:1:18 Live/Dead stain (component A: component B: molecular grade water), teased apart using sterile insect mounting needles (size 00; BioQuip, Rancho Dominguez, CA, USA), covered with a coverslip, and incubated in the dark for $15 \mathrm{~min}$. After incubation, we washed the mycelium by pulling molecular grade water through the slide mounts with bibulous paper and sealed the slides with two coats of nail polish. We used a Leica DM400B compound microscope with a 100-W mercury arc lamp for fluorescent imaging. Samples were viewed at room temperature with a Chroma Technology 35002 filter set (480-nm excitation/520-nm emission) and 100X APO oil objective.

Cultures of the $\mathrm{EHB}+$ strain of F. keratoplasticum PS0362A consistently displayed fluorescence of nucleic acids distinct from 
fungal mitochondrial or nuclear DNA (Figure 1). Combined with the absence of extrahyphal bacteria and successful amplification of Chitinophaga sp. PS-EHB01 16S rRNA genes from genomic DNA isolated directly from the fungal culture, these results served as evidence of $\mathrm{EHB}+$ status (Hoffman and Arnold, 2010; Arendt et al., 2016; Shaffer et al., 2016). Cultures of the $\mathrm{EHB}$ - strain did not contain visible fluorescence as above (Figure 1), and PCR amplification of bacterial 16S rRNA genes failed in these strains. The $\mathrm{EHB}+$ and $\mathrm{EHB}-$ status of F. keratoplasticum PS0362A strains was confirmed before and after preliminary assays and Biolog ${ }^{\circledR}$ assays (below).

\section{Preliminary Assays}

We compared colony diameter and spore production between $\mathrm{EHB}+$ and $\mathrm{EHB}-$ strains of F. keratoplasticum PS0362A by comparing five clones of each strain growing on 2\% MEA. For each clone, we placed a $4-\mathrm{mm}$ plug onto $2 \%$ MEA $(15 \mathrm{~mL})$ in a $100-\mathrm{mm}$ Petri plate. Each plug was excised from just within the growing edge of a fresh culture growing for 5 days on $2 \%$ MEA in a $100-\mathrm{mm}$ Petri plate. Plates were then incubated at $25^{\circ} \mathrm{C}$ for $10 \mathrm{~d}$. At that point the colony diameter was $c a$. $5 \mathrm{~mm}$ from the edge of a $100-\mathrm{mm}$ Petri plate, and aerial hyphae were numerous. To compare colony diameter, we marked the diameter of each clone across two orthogonal axes using a fine tip permanent marker, photographed each culture plate with aid from a tracing LED lightbox, and obtained the colony diameter for each clone by taking the average of the two axes as measured in ImageJ (Schneider et al., 2012). To compare spore production, we obtained spores from each clone by flooding the surface of the plate with $5 \mathrm{~mL}$ of sterilized milli- $\mathrm{q}_{2} \mathrm{O}\left(\mathrm{sH}_{2} \mathrm{O}\right)$, scraped the surface using a sterile rubber policeperson, and transferred the suspension to a sterile 50-mL Falcon tube (Corning, NY, USA). For each clone, we quantified the number of spores per $\mathrm{mL}$ of suspension using a hemocytometer.

\section{Biolog ${ }^{\circledR}$ Assays}

We used commercially available Biolog ${ }^{\circledR}$ microplates for phenotypic microarray assays. Biolog ${ }^{\circledR}$ filamentous fungus (FF) microplates (Catalog \#1006, Biolog Inc., Hayward, CA, USA) are 96-well microtiter plates containing 95 unique carbon sources and one negative control $\left(\mathrm{H}_{2} \mathrm{O}\right)$ (Supplementary Table 1). Substrates and reagents are pre-filled and dried into wells. Redox chemistry based on the reduction of iodonitrotetrazolium violet (INT) produces a red-colored formazan dye with peak absorbance at $490 \mathrm{~nm}$ (Bochner and Savageau, 1977; Kubicek et al., 2003). This provides a colorimetric measure of mitochondrial activity resulting from substrate use (i.e., oxidation of succinate to fumarate in the citric acid cycle causes INT to be reduced; Bochner and Savageau, 1977; Bochner, 1989; Bochner et al., 2001; Kubicek et al., 2003). Reduction of INT and production of formazan cannot be reversed, and the quantitative measure of formazan accumulation by spectrophotometry reflects oxidation of the substrate in a particular well (Bochner, 1989; Bochner et al., 2001; Kubicek et al., 2003). In turn, reading the plates at $750 \mathrm{~nm}$ measures turbidity, which reflects growth of the fungus through substrate use and production of mycelium (Kubicek et al., 2003; Druzhinina et al., 2006; Atanasova and
Druzhinina, 2010; Blumenstein et al., 2015b). Based on these measurements, the plates can distinguish even closely related strains within fungal species (Singh, 2009; Atanasova and Druzhinina, 2010).

Although FF microplates were designed for use with sporulating fungi, non-sporulating fungi can be evaluated on the plates following inoculation with homogenous hyphal suspensions (Singh, 2009). We assessed effects of EHB using hyphal suspensions for two reasons: first, the fungus produces conidia but we have not yet observed EHB in conidia of PS0362A following staining as described above (Supplementary Figure 2). Second, the fungus appears to colonize seeds as hyphae in natural conditions (Sarmiento et al., 2015).

We prepared inoculum by incubating mycelium from two clones of the $\mathrm{EHB}+$ strain and two clones of the $\mathrm{EHB}-$ strain of F. keratoplasticum PS0362A on $2 \%$ MEA at $25^{\circ} \mathrm{C}$ for $10 \mathrm{~d}$. At that point the colony diameter was $c a .5 \mathrm{~mm}$ from the edge of a $100-\mathrm{mm}$ Petri plate, and aerial hyphae were numerous, as above. We flooded the surface of each plate with $5 \mathrm{~mL}$ of $\mathrm{sH}_{2} \mathrm{O}$, scraped the surface using a sterile rubber policeperson, and combined suspension from both plates of the same EHB status by pouring into a sterile $50-\mathrm{mL}$ Falcon tube. We separated and excluded conidia by filtering the suspensions through three layers of sterile cheesecloth, discarding the filtrate, and transferring trapped hyphae to new tubes. We brought the total volume of each tube up to $20 \mathrm{~mL}$ with $0.2 \%$ carrageenan type II media (see Hobbie et al., 2003). We then transferred each suspension to a sterile Waring blender cup and blended for $20 \mathrm{~s}$. The suspension was allowed to cool for $20 \mathrm{~s}$ and then blended again for $20 \mathrm{~s}$ (see Gale et al., 1960; Orbach et al., 1996). We let each suspension rest for $10 \mathrm{~min}$ to allow large fragments to fall out of suspension, and diluted each with $0.2 \%$ carrageenan type II media to obtain an absorbance of 0.22 at $600 \mathrm{~nm}$. We added $3 \mathrm{~mL}$ of this diluted suspension to $27 \mathrm{~mL}$ of $0.2 \%$ carrageenan type II media to produce the final hyphal suspension (Hobbie et al., 2003) (Supplementary Figure 3). We allowed suspensions to sit for $6 \mathrm{~h}$ at room temperature, confirming that any remaining conidia had germinated and produced at least one septum distal to the germ tube (Supplementary Figure 3B).

We inoculated $100 \mu \mathrm{L}$ of suspension into each well of each microplate, pipetting carefully to avoid creating bubbles, and sealed each plate with a double layer of Parafilm (Bemis, Neenah, WI, USA). We prepared five replicate microplates for $\mathrm{EHB}+$ and EHB - strains, wrapped all ten plates in aluminum foil, placed them into a plastic freezer bag with moistened paper towels to prevent drying, and incubated them at $25^{\circ} \mathrm{C}$. Preliminary examination of hyphal suspension added to a synthetic glucose medium $(20 \mathrm{mM})$ confirmed viability and growth of the inocula prepared as above.

We obtained data for substrate use by reading plates at 490 $\mathrm{nm}$ (absorbance corresponding to cellular respiration) and 750 $\mathrm{nm}$ (absorbance corresponding to hyphal density) every $12 \mathrm{~h}$ for $7 \mathrm{~d}$. Plates were read using a Synergy $\mathrm{H} 1$ hybrid reader and accompanying Gen5 v.1.11 software package (BioTek, Winooski, VT, USA). We defined absorbance for a given strain on a given substrate on a given plate $\left(A_{\lambda}^{t}\right)$ as the value read at a given wavelength $(\lambda)$ at a specific time point during the experiment $(\mathrm{t})$, 


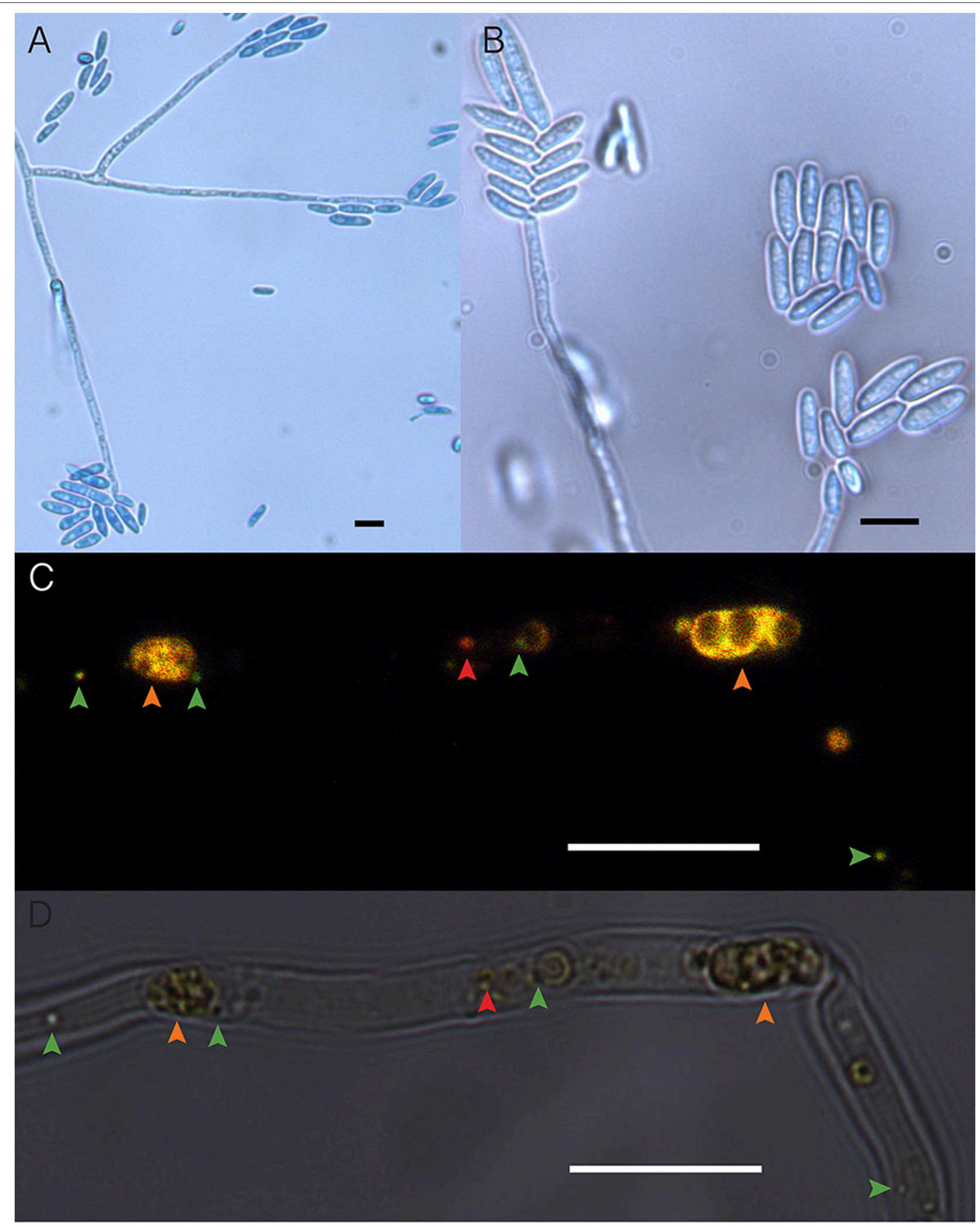




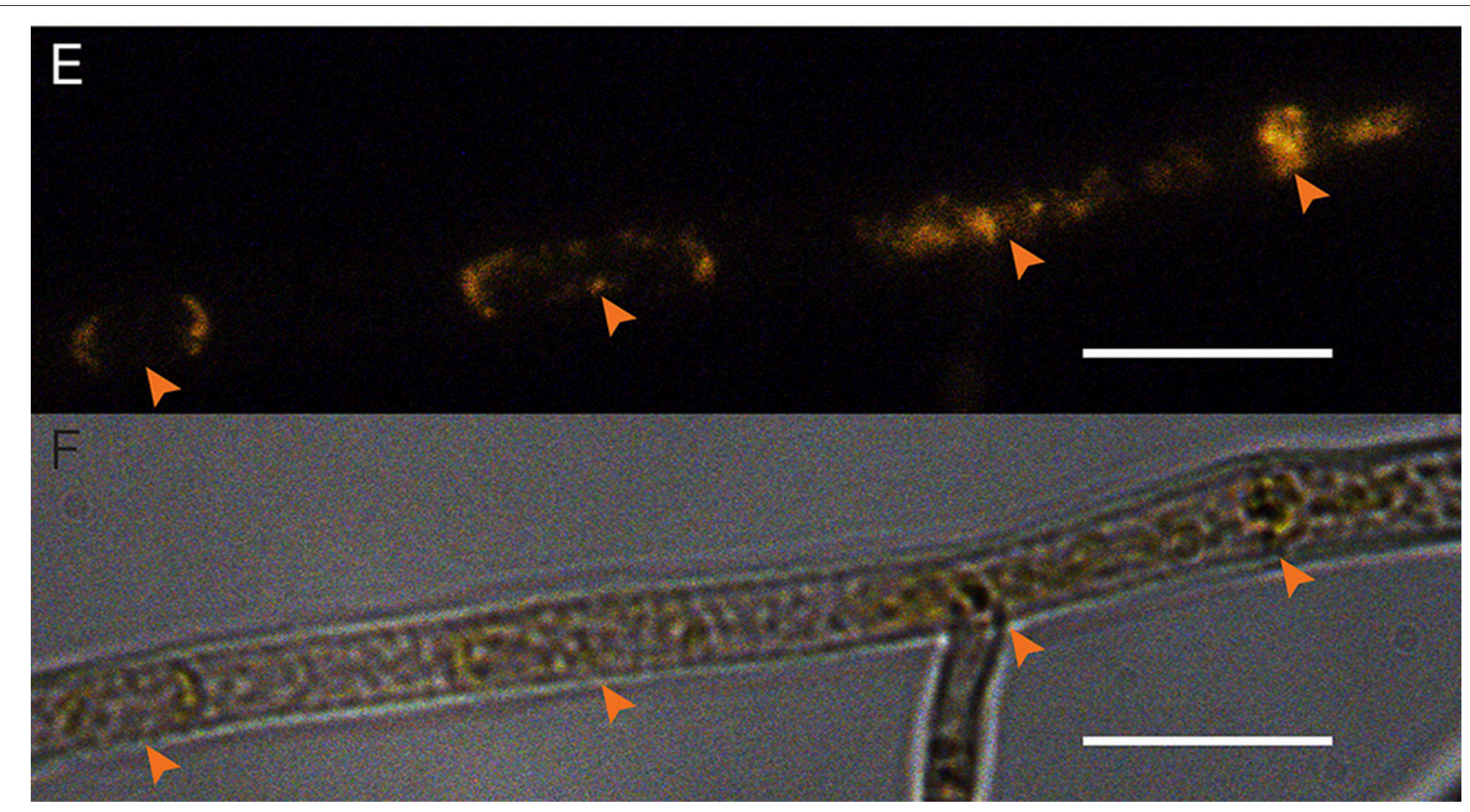

FIGURE 1 | Fusarium keratoplasticum strain PS0362A. (A) Details of culture on 2\% MEA: hyphae, conidiophores, and macroconidia. (B) Conidiophores bearing macroconidia. (C) The EHB+ strain. Fluorescently tagged nucleic acids of viable bacteria appear green, those with damaged membranes in red, and compromised fungal organelles in orange. (D) Same frame as (C) viewed with differential interference contrast (DIC). In (C,D), orange arrows indicate fungal nuclei, green arrows indicate viable EHB, and the red arrow indicates inviable EHB. (E) The cured strain (EHB-). Fluorescently tagged nucleic acids of compromised fungal organelles in orange. (F) Same frame as (E) viewed with DIC. In (E,F), orange arrows indicate fungal nuclei. In all images fungal mycelium was alive at the outset of preparation but was inactivated during the visualization process. Scale bars $=10 \mu \mathrm{m}$.

and total absorbance by a given strain on a given substrate $\left(\bar{A}_{\lambda}^{t}\right)$ as the mean absorbance from five replicate plates, measured at a given wavelength $(\lambda)$ at a specified time point during the experiment (t). As previous studies have shown the absorbance spectrum of hyaline mycelium to be level over wavelengths from 490 to $750 \mathrm{~nm}$, an adjusted redox value for the production of formazan is obtained by subtracting the absorbance for hyphal density $(750 \mathrm{~nm})$ from that for cellular respiration $(490 \mathrm{~nm}$; Tanzer et al., 2003; Atanasova and Druzhinina, 2010). We therefore define the corrected absorbance at $490 \mathrm{~nm}$ as $A_{\mathrm{c} 490}=$ $A_{490}-A_{750}$.

Absorbance measurements corresponding to respiration $\left(A_{c 490}\right)$ and hyphal density $\left(A_{750}\right)$ were highly positively correlated (Kendall's $\tau=0.68, p<2.2 \times 10^{-16}$; Figure 2). Furthermore, because similar studies may use indicator dyes other than INT (see Bochner and Savageau, 1977) and redoxbased color formation by filamentous fungi does not always correlate with growth as with bacteria and yeasts (Atanasova and Druzhinina, 2010), absorbance values corresponding to hyphal density $(750 \mathrm{~nm})$ are more consistent across different growth conditions and hyphal morphologies. Absorbance values corresponding to hyphal density also are more often reported and therefore more comparable among studies (Tanzer et al., 2003; Atanasova and Druzhinina, 2010). Thus, we focus our results on measurements of absorbance (i.e., turbidity) corresponding to hyphal density $\left(A_{750}\right)$, which we refer to as growth (below).

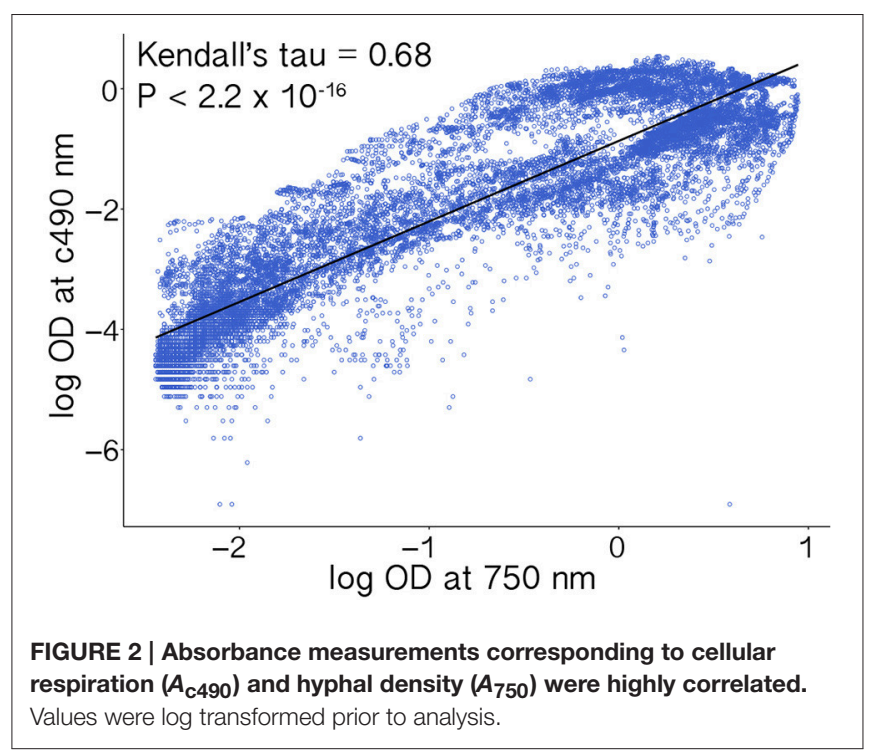

Measurable growth was defined as $0.3<A_{750}^{7} \leq 3.0$ (see Figure 3), where the upper bound represents $99.9 \%$ light absorbance and the lower bound the value that best differentiates growth in the lag phase (i.e., negligible growth) from that reaching the log/exponential phase, across all substrates. We 


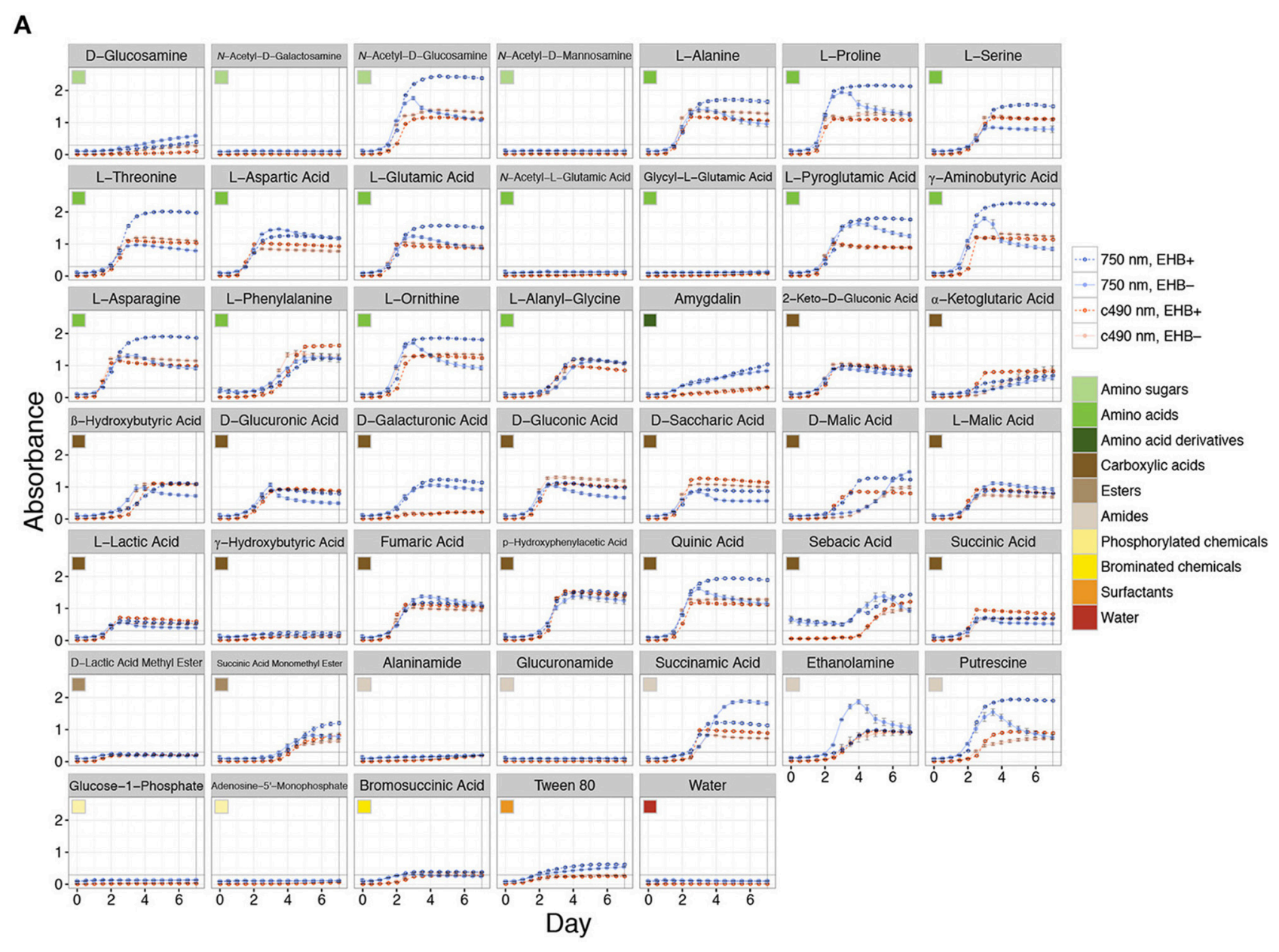

FIGURE 3 | Continued

recognized absorbance values at which strains reach stationary phase as representing the maximum capacity for growth on that substrate. We observed a range of growth corresponding to $0.31 \leq A_{750}^{7} \leq 2.54$. Overall we recognized five major outcomes: (1) negligible growth by both EHB+ and EHBstrains $\left(A_{750}^{7} \leq 0.3\right)$, (2) measurable growth by both, but no difference in growth between $\mathrm{EHB}+$ and $\mathrm{EHB}-$ strains, (3) measurable growth by the $\mathrm{EHB}+$ strain but negligible growth by the EHB - strain, (4) measurable growth by both, with the EHB - strain reaching a higher density, and (5) measurable growth by both, with the $\mathrm{EHB}+$ strain reaching a higher density.

\section{Statistical Analyses}

For preliminary assays, we compared colony diameter and spore production between $\mathrm{EHB}+$ and $\mathrm{EHB}-$ strains using Welch $t$-tests. For Biolog ${ }^{\circledR}$ assays, we compared differences in global substrate use (i.e., growth across all substrates) between $\mathrm{EHB}+$ and $\mathrm{EHB}$ - strains of F. keratoplasticum PS0362A using hierarchical clustering and permutational multivariate analysis of variance (PERMANOVA; Anderson, 2001; Anderson and ter Braak, 2003) based on the Bray-Curtis dissimilarity metric, as implemented in the $\mathrm{R}$ package vegan ( $\mathrm{R}$ Core Team, 2015; Oksanen et al., 2016). For each time point, we first calculated dissimilarities among all replicate plates considering growth across all substrates. We then visualized global differences in substrate use among plates by constructing cluster dendrograms, and analyzed differences between plates inoculated with $\mathrm{EHB}+$ and $\mathrm{EHB}-$ strains using PERMANOVA ( $n=1,000$ permutations). We further explored differences using non-parametric analysis of similarity (ANOSIM; $n=$ 1,000 permutations; Clarke and Green, 1988; Clarke, 1993) and multi-response permutation procedures (MRPP; $n=1,000$ permutations; Biondini et al., 1985), but given the normality of the data we focus here on results from PERMANOVA. We made comparisons for each time point in order to determine the time at which the global effect was largest. We then used that time point to evaluate differences in $A_{750}$ between $\mathrm{EHB}+$ vs. $\mathrm{EHB}$ - strains for focal substrates using Welch $t$ tests. We controlled for the rate of type I errors inherent in making multiple comparisons by using the false discovery ratecontrolling method of Benjamini and Hochberg (1995). The raw data and $\mathrm{R}$ scripts for all analyses are available online (Shaffer, 2017). 


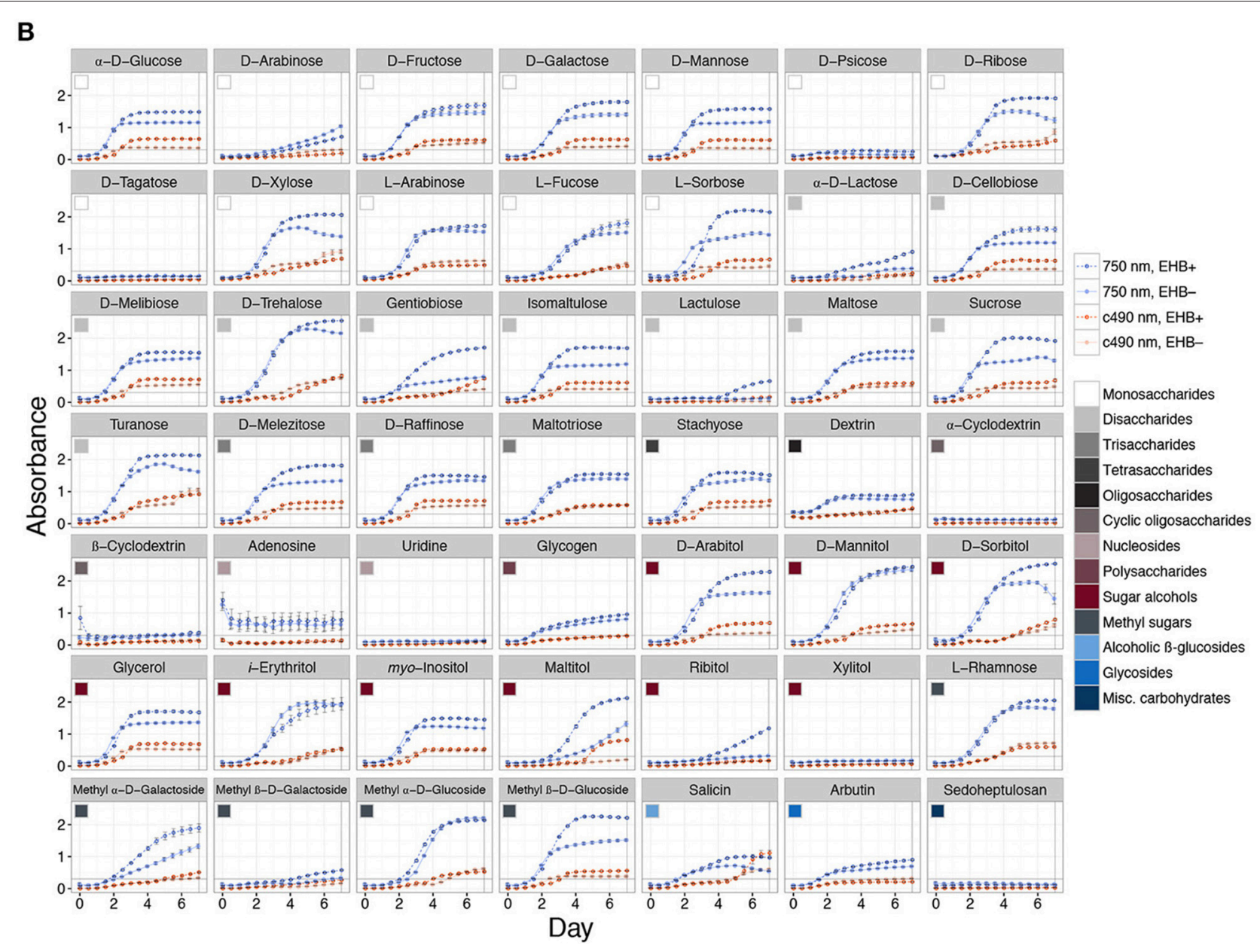

FIGURE 3 | Total absorbance for EHB+ and EHB- strains of Fusarium keratoplasticum PS0362A across all substrates on Biolog ${ }^{\circledR}$ phenotypic microarrays over 7 d. Light- and dark-orange lines represent absorbance at $490 \mathrm{~nm}$ (i.e., cellular respiration). Light- and dark-blue lines represent absorbance at $750 \mathrm{~nm}$ (i.e., hyphal density, defined here as growth). Dark, dotted lines with open circles indicate absorbance for EHB+ strains. Light, solid lines with filled circles indicate absorbance for EHB - strains. Colored squares indicate different substrate classes. The horizontal line at Absorbance $=0.3$ indicates the minimum absorbance value recognized. The vertical line at Day $=7$ indicates the time point for which absorbance values were formally compared. (A) Sugar-based substrates. (B) Amino- and carboxylic acids, their derivatives, and other substrates.

\section{RESULTS}

Naturally infected (EHB+) and cured (EHB-) strains of F. keratoplasticum PS0362A were stable under laboratory conditions and grew readily on standard growth media and on diverse substrates in Biolog ${ }^{\circledR}$ assays. Both colony diameter and spore production by $\mathrm{EHB}+$ and $\mathrm{EHB}-$ strains were similar on 2\% MEA (Supplementary Figures 4, 5). However, in Biolog ${ }^{\circledR}$ assays, growth by the fungus was significantly influenced by the presence of the EHB Chitinophaga sp. PS-EHB01 across the majority of carbon sources (Figure 3 and Supplementary Figure 6, Table 1).

Overall the EHB+ strain used 79 of 95 carbon sources (Figure 3, Table 1). The EHB- strain used 77 of 95 of carbon sources, including all of those used by the EHB+ strain except for one disaccharide and one brominated chemical (see below; Figure 3 and Supplementary Figure 6, Table 1).

Global substrate use (i.e., growth across all substrates considered simultaneously) differed significantly between EHB+ and $\mathrm{EHB}-$ strains after 1 day and differentiated further throughout the remainder of the experiment (Figure 4, Table 2). For many substrates the initial growth rates of $\mathrm{EHB}+$ and $\mathrm{EHB}-$ strains were similar; however, the hyphal densities at which EHB - strains reached stationary phase were often significantly lower than those at which $\mathrm{EHB}+$ strains reached stationary phase (e.g., $N$-acetyl-D-glucosamine, L-proline, $\gamma$-aminobutyric acid, L-ornithine, quinic acid, D-gluconic acid, putrescine; Figure 3, Table 1). PERMANOVA indicated that global differences were greatest at $7 \mathrm{~d}$ (Figure 4D, Table 2); therefore, we used this time point for comparing growth between $\mathrm{EHB}+$ and $\mathrm{EHB}-$ 
TABLE 1 | Comparison of total absorbance at $750 \mathrm{~nm}$ at $7 \mathrm{~d}\left(A_{750}^{7}\right)$ between EHB+ and EHB- strains of $F$. keratoplasticum PS0362A.

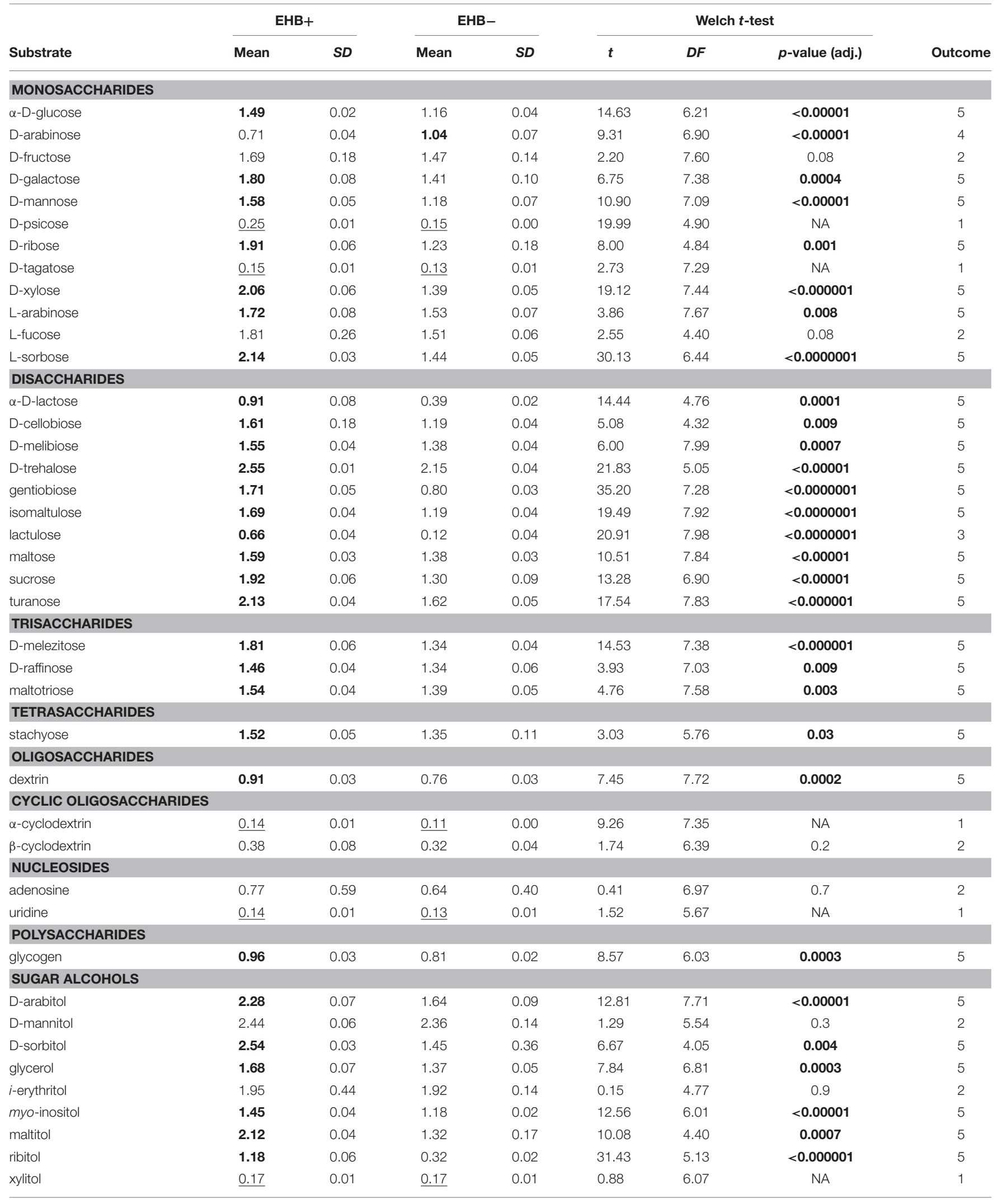


TABLE 1 | Continued

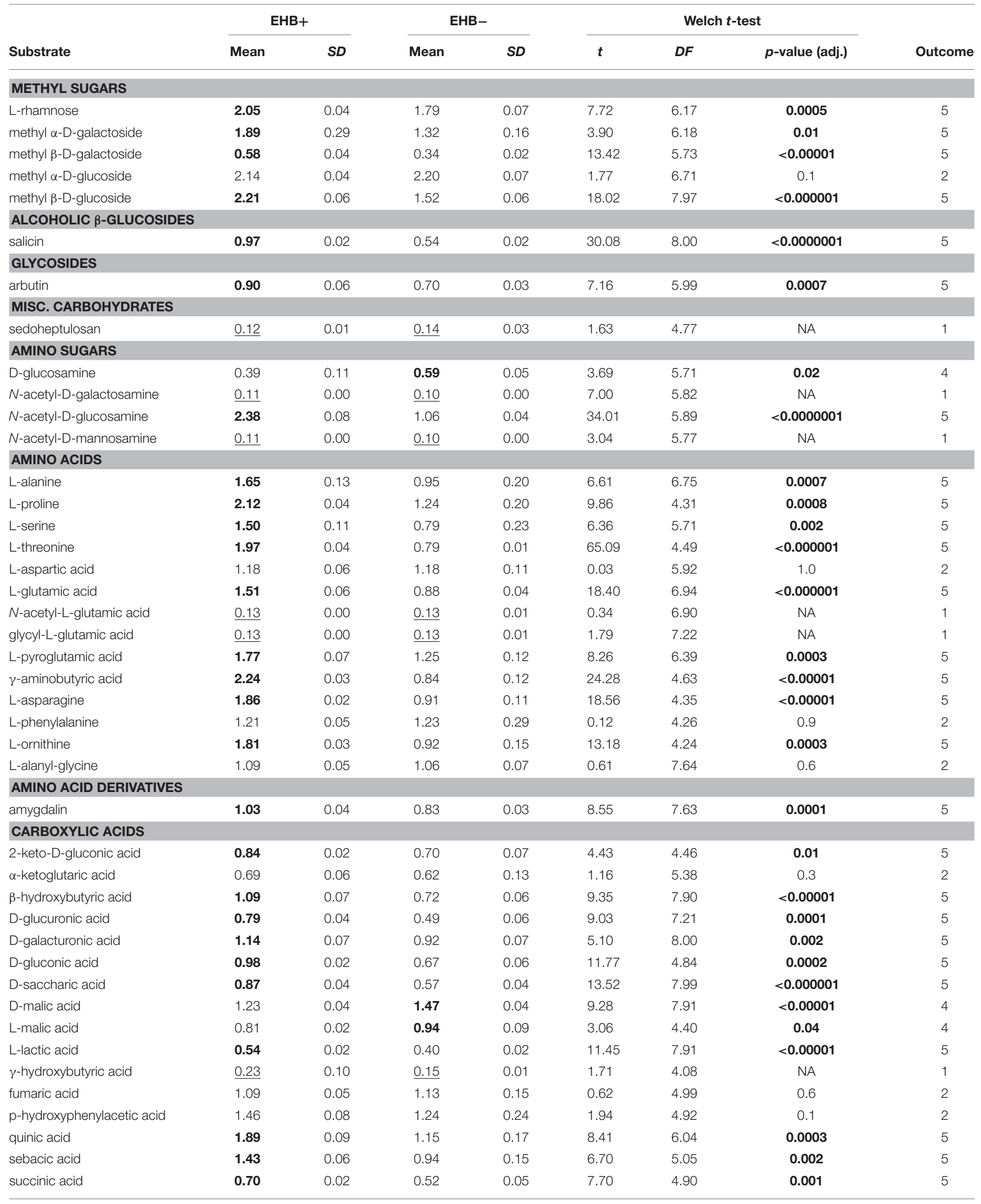




\begin{tabular}{|c|c|c|c|c|c|c|c|c|}
\hline Substrate & \multicolumn{2}{|c|}{$\mathrm{EHB}+$} & \multicolumn{2}{|c|}{ EHB- } & \multicolumn{3}{|c|}{ Welch $t$-test } & Outcome \\
\hline \multicolumn{9}{|l|}{ ESTERS } \\
\hline D-lactic acid methyl ester & $\underline{0.22}$ & 0.00 & $\underline{0.17}$ & 0.00 & 15.96 & 8.00 & NA & 1 \\
\hline $\begin{array}{l}\text { succinic acid monomethyl } \\
\text { ester }\end{array}$ & 1.20 & 0.11 & 0.79 & 0.16 & 4.76 & 6.87 & 0.004 & 5 \\
\hline glucuronamide & $\underline{0.10}$ & 0.01 & $\underline{0.11}$ & 0.00 & 3.21 & 5.48 & NA & 1 \\
\hline succinamic acid & 1.13 & 0.10 & 1.82 & 0.13 & 9.78 & 7.48 & $<0.00001$ & 4 \\
\hline ethanolamine & 0.92 & 0.04 & 1.05 & 0.21 & 1.41 & 4.23 & 0.3 & 1 \\
\hline putrescine & 1.90 & 0.06 & 0.77 & 0.18 & 13.66 & 4.76 & 0.0001 & 5 \\
\hline \multicolumn{9}{|c|}{ PHOSPHORYLATED CHEMICALS } \\
\hline bromosuccinic acid & 0.38 & 0.02 & 0.25 & 0.01 & 13.54 & 7.90 & $<0.000001$ & 3 \\
\hline \multicolumn{9}{|l|}{ SURFACTANTS } \\
\hline Tween $^{\circledR} 80$ & 0.62 & 0.06 & 0.55 & 0.03 & 2.25 & 5.63 & 0.09 & 2 \\
\hline water & $\underline{0.11}$ & 0.00 & $\underline{0.10}$ & 0.00 & 2.98 & 6.86 & NA & 1 \\
\hline
\end{tabular}

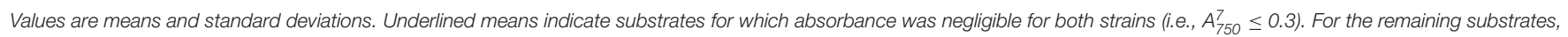

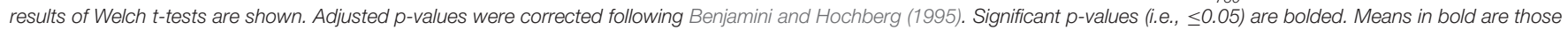
that were found to be significantly greater in comparisons. For each substrate, one of five observed outcomes is listed (see Section Results).

strains on individual substrates. We classified our results into four general outcomes, as described below.

The 17 substrates on which we observed negligible growth by both the $\mathrm{EHB}+$ and $\mathrm{EHB}$ - strains (Outcome 1) included diverse monosaccharides (e.g., D-psicose), amino sugars (e.g., $N$-acetylD-galactosamine), amino acids (e.g., glycyl-L-glutamic acid), amides (e.g., alaninamide), and phosphorylated chemicals (e.g., glucose-1-phosphate), in addition to water (Figure 3, Table 1).

$\mathrm{EHB}+$ and $\mathrm{EHB}$ - strains both used, but did not differ in growth on, 15 substrates (Outcome 2; Figure 3, Table 1). These included diverse monosaccharides (e.g., D-fructose), sugar alcohols (e.g., D-mannitol), amino acids (e.g., phenylalanine), and carboxylic acids (e.g., fumaric acid).

On two substrates we observed measurable growth by the $\mathrm{EHB}+$ strain and negligible growth by the $\mathrm{EHB}-$ strain (Outcome 3). These were lactulose and bromosuccinic acid, on which the $\mathrm{EHB}+$ strain only grew to $A_{750}^{7}=0.66$ and 0.39 , respectively (Figure 3 , Table $\mathbf{1}$ ).

We observed measurable and significantly different growth between $\mathrm{EHB}+$ and $\mathrm{EHB}-$ strains on 64 carbon sources (Figure 3, Table 1). The $\mathrm{EHB}$ - strain grew to a higher density on five substrates (Outcome 4), including one monosaccharide (D-arabinose), two stereoisomeric forms of one carboxylic acid (D- and L-malic acid), and one amide (succinamic acid; Figure 3, Table 1). The EHB + strain grew to a higher density on 59 substrates (Outcome 5), including over three-quarters of all sugar-based substrates (77\%), and most amino- and carboxylic acids and their derivatives (58 and 60\%, respectively) (Figure 3, Table 1).
We repeated the experiment by re-curing the naturally infected strain and performing the Biolog ${ }^{\circledR}$ trial a second time. The raw data and code for analyses are available online (Shaffer, 2017). Results were consistent with those reported here.

\section{DISCUSSION}

Endohyphal bacteria (EHB) have been documented as symbionts in phylogenetically and ecologically diverse lineages of fungi (Barbieri et al., 2000; Bianciotto et al., 2003; Bertaux et al., 2005; Partida-Martínez et al., 2007b; Sharma et al., 2008; Hoffman and Arnold, 2010; Sato et al., 2010; Desirò et al., 2015; Shaffer et al., 2016). Only in a few cases have their effects been explored. Comparative genomics and phenotypic assays have recently highlighted the importance of certain proteobacterial EHB among foliar endophytic Ascomycota (Arendt, 2015; Baltrus et al., 2016). Here we provide the first insight to the influence of EHB on broad-spectrum substrate use by a member of a clade of fungi known for their widespread pathogenicity on plants (i.e., the $F$. solani species complex), with a focus on a strain affiliated with seeds from tropical forest soil. The strain considered here is a member of a lineage that is known for ecologically and medically important strains (i.e., F. keratoplasticum; Short et al., 2013). Its endohyphal bacterium belongs to a genus known for their production of secondary metabolites with antimicrobial activity (i.e., Chitinophaga). More broadly, it is a member of the Bacteroidetes, a phylogenetically diverse phylum of Gramnegative bacteria that are globally distributed, exhibit many 
A $\quad \mathrm{OD}_{750}$ at 1 day

$F_{1,8}=2.5, R^{2}=0.24, P=0.07$

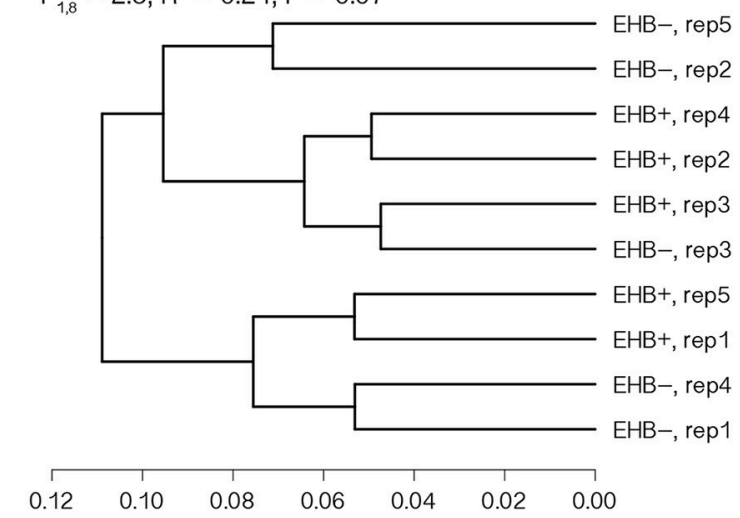

C

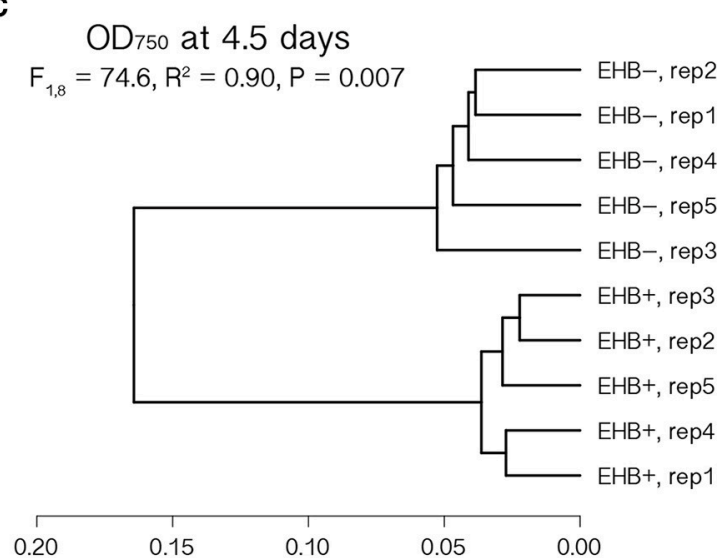

B $\quad \mathrm{OD}_{750}$ at 2 days

$F_{1,8}=22.6, R^{2}=0.74, P=0.008$
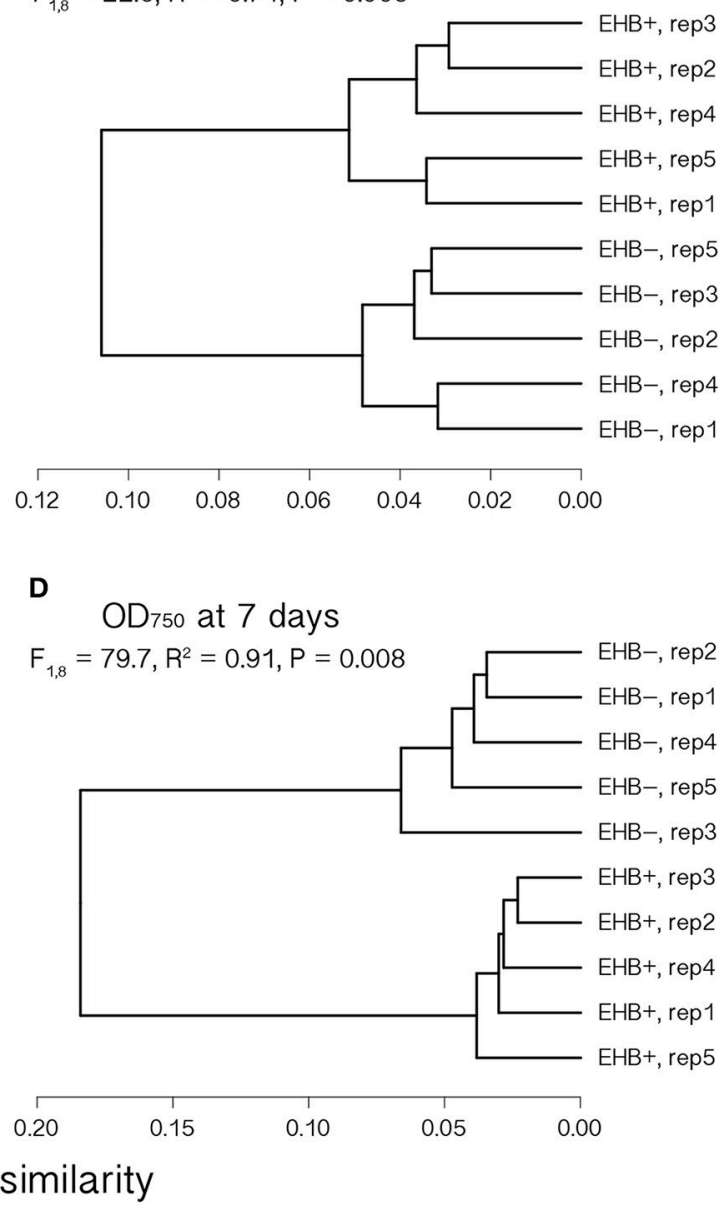

FIGURE 4 | Cluster dendrograms summarizing differences in global substrate use at 1, 2, 4.5, and 7 d among EHB+ and EHB-replicate Biolog ${ }^{\circledR}$ PMs. Distances represent Bray-Curtis dissimilarities. Results from a permutational multivariate analysis of variance (PERMANOVA) are shown for each time point. Panels show differences at (A) $1 \mathrm{~d}$, (B) $2 \mathrm{~d}$, (C) $4.5 \mathrm{~d}$, and (D) $7 \mathrm{~d}$.

biological functions, and are well-known symbionts of mammals and insects as well as degraders of organic matter (Moran et al., 2005; Thomas et al., 2011). Similar to Proteobacteria, Bacteroidetes are often one of the most representative taxa recovered from environmental sampling of freshwater, soil, animals guts and skin, and especially the phyllosphere (Redford et al., 2010; Thomas et al., 2011). To our knowledge, no endohyphal member of the Bacteroidetes has been examined previously for its associations with fungi or its phenotypic effects on a fungal host.

\section{Phenotypic Microarrays}

Phenotypic microarrays (PMs) provide a means to obtain quantitative data in a reproducible and highly controlled manner with respect to biomass accumulation from the metabolism of specific compounds. Such data can inform diverse and emerging fields concerning microbial ecology such as community systems biology and metametabolomics, and can provide the basis for hypotheses that can be evaluated in the context of genomics and transcriptomics analyses.

Recently PMs have been used to address questions in fungal ecology and evolution, including those relevant to biotechnology applications (Greetham, 2014; Blumenstein et al., 2015a), evolutionary relationships and species concepts (Rice and Currah, 2005; Atanasova et al., 2010), carbon dynamics and niche differentiation (Lee and Magan, 1999; Hobbie et al., 2003; Friedl et al., 2008), genetic and functional diversity (Dobranic and Zak, 1999; Druzhinina et al., 2006; Grizzle and Zak, 2006; Friedl et al., 2008), and ecophysiology (Druzhinina et al., 2010). Here we used a Biolog ${ }^{\circledR}$ plate assay as a rapid and simple method for use in characterizing the influence of EHB on broad-spectrum carbon source use by a filamentous fungus.

We found that the presence of Chitinophaga sp. PS-EHB01 significantly influenced substrate use across over two-thirds (67\%) of carbon sources. The EHB+ strain grew to a higher absorbance compared to the $\mathrm{EHB}-$ strain across the majority 
TABLE 2 | Summary of differences in global substrate use between EHB+ and EHB- strains over $7 \mathrm{~d}$.

\begin{tabular}{|c|c|c|c|c|c|c|c|}
\hline \multirow[b]{2}{*}{ Day } & \multicolumn{3}{|c|}{ PERMANOVA } & \multicolumn{2}{|c|}{ ANOSIM } & \multicolumn{2}{|c|}{ MRPP } \\
\hline & $\boldsymbol{F}$ & $R^{2}$ & $p$-value & $R$ & $p$-value & $A$ & $p$-value \\
\hline 0.5 & 0.97 & 0.11 & 0.4 & 0.004 & 0.5 & $<0.0$ & 0.5 \\
\hline 1.0 & 2.48 & 0.24 & 0.07 & 0.33 & 0.07 & 0.07 & 0.08 \\
\hline 1.5 & 6.86 & 0.46 & 0.009 & 1.00 & 0.003 & 0.23 & 0.02 \\
\hline 2.0 & 22.60 & 0.74 & 0.008 & 1.00 & 0.005 & 0.42 & 0.01 \\
\hline 2.5 & 18.10 & 0.69 & 0.009 & 1.00 & 0.01 & 0.40 & 0.009 \\
\hline 3.0 & 35.19 & 0.81 & 0.008 & 1.00 & 0.01 & 0.51 & 0.009 \\
\hline 3.5 & 57.42 & 0.88 & 0.01 & 1.00 & 0.007 & 0.59 & 0.005 \\
\hline 4.0 & 75.49 & 0.90 & 0.007 & 1.00 & 0.01 & 0.63 & 0.01 \\
\hline 4.5 & 74.62 & 0.90 & 0.007 & 1.00 & 0.008 & 0.63 & 0.01 \\
\hline 5.0 & 75.12 & 0.90 & 0.01 & 1.00 & 0.01 & 0.64 & 0.006 \\
\hline 5.5 & 71.26 & 0.90 & 0.01 & 1.00 & 0.004 & 0.63 & 0.007 \\
\hline 6.0 & 72.46 & 0.90 & 0.01 & 1.00 & 0.009 & 0.63 & 0.02 \\
\hline 6.5 & 78.24 & 0.91 & 0.006 & 1.00 & 0.007 & 0.64 & 0.01 \\
\hline 7.0 & 79.72 & 0.91 & 0.008 & 1.00 & 0.01 & 0.65 & 0.01 \\
\hline
\end{tabular}

Bray-Curtis dissimilarities based on growth across all substrates were calculated for each pair of replicate phenotypic microarrays, which were grouped based on inoculation with $E H B+v s$. EHB - strains. Results from three different methods (permutational multivariate analysis of variance [PERMANOVA], analysis of similarity [ANOSIM], and multi-response permutation procedure [MRPP]) confirm that significant differences in global substrate use between $E H B+$ and EHB- strains were observed and maintained after one day. Significant p-values (i.e., $\leq 0.05$ ) are bolded.

of substrates (62\%). In general, initial growth rates of EHB+ and $\mathrm{EHB}$ - strains were similar; however, the absorbance values at times after which the EHB - strain reached stationary phase were significantly lower than for those for when the $\mathrm{EHB}+$ strain reached stationary phase (Figure 3, Table 1). We speculate that the bacterium may serve as a metabolic enhancer, possibly releasing compounds that serve as growth factors for the host fungus, or by detoxifying or metabolizing otherwise harmful waste or growth byproducts such as reactive oxygen species known to accumulate from catabolism of certain compounds (e.g., L-ornithine, putrescine; Pegg and Casero, 2011; Salvioli et al., 2016; Vannini et al., 2016). That Chitinophaga sp. PS-EHB01 appears to be consistently associated with F. keratoplasticum PS0362A but cannot be isolated into pure culture on standard media (Shaffer, unpublished) suggests that this EHB may rely on its host fungus to acquire essential nutrients.

\section{Perspectives from Related Species}

Although their genomes have not yet been sequenced, genomic data are available for close relatives of the bacterium and fungus evaluated here (see Coleman et al., 2008; Del Rio et al., 2010). The focal bacterium is closely related to Chitinophaga pinensis (Supplementary Figure 7), which was isolated originally from soil and is known for its ability to degrade chitin (Sangkhobol and Skerman, 1981). Chitinophaga pinensis also produces antibiotics with activity against a diversity of filamentous fungi (Mohr et al., 2015). That species possesses multiple genes predicted to be involved in the metabolism of carbohydrates $(n=330)$ and amino acids $(n=301$; Del Rio et al., 2010). The focal bacterium is also closely related to C. arvensicola (Supplementary
Figure 7), a bacterium associated with amphibian skin that produces metabolites with inhibitory effects on the notorious fungal pathogen Batrachochytrium dendrobatidis, causal agent of chytridiomycosis (Loudon et al., 2014). Whether such traits are common in the Chitinophaga strain examined here remains to be determined.

Using a three-locus dataset, we showed previously that $F$. keratoplasticum PS0362A is part of the F. solani species complex (FSSC). The fungus studied here is closely related to FSSC Clade 3 haplotype group 2 (Shaffer et al., 2016). The closest relative with publicly available genomic data, Nectria haematococca MPVI, is in group 11-c (Short et al., 2013; Shaffer et al., 2016). Nectria haematococca MPVI occurs as a saprotroph and plant pathogen in diverse habitats (Coleman et al., 2008). Many members of the FSSC have conditionally dispensable, supernumerary chromosomes (CD chromosomes) that can influence the use of specific carbon sources (Covert, 1998; Coleman et al., 2008). $\mathrm{CD}$ chromosomes are mitotically stable in $\mathrm{N}$. haematococca MPVI (Covert, 1998). Therefore, it is likely that the phenotypic results observed here do not reflect differential presence of $C D$ chromosomes between $\mathrm{EHB}+$ and $\mathrm{EHB}-$ strains, but rather a difference in the presence of the bacterium between them.

The genome of $N$. haematococca is highly enriched with genes coding for carbohydrate-active enzymes, including glycoside hydrolase and polysaccharide lyase genes (Coleman et al., 2008). Nectria haematococca also possesses a high number of ATP-binding cassette $(\mathrm{ABC})$ transporter genes, second only to Aspergillus oryzae when compared to 10 other members of the Dikarya (Coleman et al., 2008). That the fungus studied here was able to use the majority of carbon sources regardless of EHB infection status may reflect similar gene composition. These substrates included some synthetic, nonnatural compounds such as lactulose, bromosuccinic acid, and Tween ${ }^{\circledR} 80$, emphasizing the metabolic breadth of this fungus. Strikingly, that breadth is increased markedly by the presence of Chitinophaga sp. PS-EHB01 as an EHB. Once data for both the bacterium and fungus are available, comparative genomics and transcriptomics can be used to understand metabolic interactions between the pair. More broadly, the pair could be developed to become a model system for understanding EHB of plantassociated Ascomycota.

\section{Implications for Seed-Fungus Interactions}

Fungi recruit from soil to seeds that have been dispersed to the soil seed bank, thus undergoing horizontal transmission (rather than being vertically transmitted from mother to offspring) (U'Ren et al., 2009; Sarmiento et al., 2015; Zalamea et al., 2015; Sarmiento et al., unpublished). Given this life history, seedfungus interactions at the soil-seed interface (i.e., those involving the seed coat) are of primary interest with regard to community assembly of fungi in seeds. Furthermore, similar to bud-break or wounding (Agrios, 1997; Schädel et al., 2009; Gordon and Leveau, 2010; Savatin et al., 2014), seed germination represents a key event during which nutrients that may attract potential symbionts are released into the environment. The potential for EHB to influence seed-fungus interactions during colonization of 
seeds by fungi at the soil-seed interface, and during key plant lifestage transitions such as seed germination, should be investigated further.

Here we showed that the presence vs. absence of Chitinophaga sp. PS-EHB01 led to differential growth by F. keratoplasticum on most sugars, amino acids, and carboxylic acids, nearly all of which are relevant in plant biology. In particular, a number of substrates are important in the ecology of seeds, such as important global regulators (e.g., D-trehalose and myo-inositol; Loewus and Murthy, 2000; Grennan, 2007; Henry et al., 2014; Lunn et al., 2014), those metabolized or produced during seed imbibition and germination (e.g., D-trehalose, sucrose, D-raffinose, stachyose, dextrin, and L-asparagine; Atkins et al., 1975; Bewley and Black, 1978; Kuo et al., 1990; Queiroz and Cazetta, 2016), as well as those important in the metabolism of seed structural components such as the seed coat (e.g., D-mannose, L-arabinose, sucrose, D-raffinose, stachyose, myo-inositol, and L-alanine; Herold and Lewis, 1977; Bewley and Black, 1978; Kuo et al., 1990; Buckeridge et al., 2000; Loewus and Murthy, 2000; Lahuta et al., 2007; Kosina et al., 2013). The average difference in growth between EHB+ and $\mathrm{EHB}$ - strains, considering only those substrates on which we observed significant differences $\left(n=64\right.$; Table 1) was $A_{750}^{7}=$ 0.3 . Whether this difference scales to meaningful changes with regard to interacting with plants in nature is not yet known, and will be assessed in future work using seed-infection and seedgermination experiments. We anticipate that changes in fungal substrate use by EHB will alter phenotypes that in turn define both the fungal niche and the outcomes of interactions with hosts.

\section{AUTHOR CONTRIBUTIONS}

JU modified and tested the phenotypic microarray experimental protocol for use with fungal hyphal fragments; JS made additional

\section{REFERENCES}

Agrios, G. N. (1997). Plant Pathology. San Diego, CA: Academic Press.

Anca, I., Lumini, E., Ghignone, S., Salvioli, A., Bianciotto, V., and Bonfante, P. (2009). The fts $Z$ gene of the endocellular bacterium 'Candidatus Glomeribacter gigasporarum' is preferentially expressed during the symbiotic phases of its host mycorrhizal fungus. Mol. Plant-Microbe Interact. 22, 302-310. doi: 10.1094/MPMI-22-3-0302

Anderson, M. J. (2001). A new method for non-parametric multivariate analysis of variance. Austral Ecol. 26, 32-46. doi: 10.1111/j.1442-9993.2001. 01070.pp.x

Anderson, M. J., and ter Braak, C. J. F. (2003). Permutational tests for multi-factorial analysis of variance. J. Stat. Comput. Simul. 73, 85-113. doi: 10.1080/00949650215733

Arendt, K. A. (2015). Symbiosis Establishment and Ecological Effects of Endohyphal Bacteria on Foliar Fungi. Master's thesis, University of Arizona, Tucson, AZ.

Arendt, K. A., Hockett, K. L., Araldi-Brondolo, S. J., Baltrus, D. A., and Arnold, A. E. (2016). Isolation of endohyphal bacteria from foliar Ascomycota and in vitro establishment of their symbiotic associations. Appl. Environ. Microbiol. 82, 2943-2949. doi: 10.1128/AEM.00452-16

Arnold, A. E., and Engelbrecht, B. M. J. (2007). Fungal endophytes nearly double minimum leaf conductance in seedlings of a neotropical tree species. J. Trop. Ecol. 23, 369-372. doi: 10.1017/S0266467407004038 modifications to exclude fungal spores, and performed all experimental work and related data analysis; AA and DB advised aspects of the data analysis; JS and AA led the development of the manuscript, with contributions from DB, RG, and JU.

\section{FUNDING}

We thank the National Science Foundation (NSF DEB-1119758 to AA, NSF DEB-1120205 to James W. Dalling, NSF IOS1354219 to DB, AA, and RG, NSF-IGERT Fellowship to JS), the Smithsonian Tropical Research Institute (STRI) (Short-term Fellowship to JS), the Mycological Society of America (Forest Fungal Ecology Award to JS), and the Graduate and Professional Student Council (Research Award to JS) and School of Plant Sciences (Pierson Fellowship to JS) at The University of Arizona for supporting this work. Additional support from the School of Plant Sciences and College of Agriculture and Life Sciences at the University of Arizona is gratefully acknowledged.

\section{ACKNOWLEDGMENTS}

We thank J. DeVore, K. Hockett, and especially A. Ndobegang for lab assistance, K. Arendt, Y.-L. Huang, J. Carlson, K. Hockett, J. Dalling, J. Wright, E. Leigh, G. Gilbert, and N. Zimmerman for helpful discussion, and N. Zimmerman for bioinformatics assistance. This paper represents a portion of the doctoral dissertation research of JS in Plant Pathology and Microbiology at the University of Arizona.

\section{SUPPLEMENTARY MATERIAL}

The Supplementary Material for this article can be found online at: http://journal.frontiersin.org/article/10.3389/fmicb. 2017.00350/full\#supplementary-material
Arnold, A. E., and Lutzoni, F. (2007). Diversity and host range of foliar fungal endophytes: are tropical leaves biodiversity hotspots? Ecology 88, 541-549. doi: 10.1890/05-1459

Arnold, A. E., Mejia, L. C., Kyllo, D., Rojas, E. I., Maynard, Z., Robbins, N., et al. (2003). Fungal endophytes limit pathogen damage in a tropical tree. Proc. Natl. Acad. Sci. U.S.A. 100, 15649-15654. doi: 10.1073/pnas.2533483100

Atanasova, L., and Druzhinina, I. S. (2010). Global nutrient profiling by Phenotypic MicroArrays: a tool complementing genomic and proteomic studies in conidial fungi. J. Zhejiang Univ. Sci. B 11, 151-168. doi: 10.1631/jzus.B1000007

Atanasova, L., Jaklitsch, W. M., Komon-Zelazowska, M., Kubicek, C. P., and Druzhinina, I. S. (2010). Clonal species of Trichoderma parareesei sp. nov. likely resembles the ancestor of the cellulase producer Hypocrea jecorina/T. reesei. Appl. Environ. Microbiol. 76, 7259-7267. doi: 10.1128/AEM.01184-10

Atkins, C. A., Pate, J. S., and Sharkey, P. J. (1975). Asparagine metabolism - key to the nitrogen nutrition of developing legume seeds. Plant Physiol. 56, 807-812. doi: 10.1104/pp.56.6.807

Baltrus, D. A., Dougherty, K., Arendt, K. R., Huntemann, M., Clum, A., Pillay, M., et al. (2016). Absence of genome reduction in diverse, facultative endohyphal bacteria. Microb. Genom. doi: 10.1099/mgen.0.000101. [Epub ahead of print].

Barbieri, E., Potenza, L., Rossi, I., Sisti, D., Giomaro, G., Rossetti, S., et al. (2000). Phylogenetic characterization and in situ detection of Cytophaga-Flexibacter-Bacteroides phylogroup bacterium in Tuber borchii Vittad. ectomycorrhizal mycelium. Appl. Environ. Microbiol. 66, 5035-5042. doi: 10.1128/AEM.66.11.5035-5042.2000 
Benjamini, Y., and Hochberg, Y. (1995). Controlling the false discovery rate: a practical and powerful approach to multiple testing. J. R. Stat. Soc. B 57, 289-300.

Bertaux, J., Schmid, M., Hutzler, P., Hartmann, A., Garbaye, J., and Frey-Klett, P. (2005). Occurrence and distribution of endobacterial in the plant-associated mycelium of the ectomycorrhizal fungus Laccaria bicolor S238N. Environ. Microbiol. 7, 1786-1795. doi: 10.1111/j.1462-2920.2005.00867.x

Bewley, J. D., and Black, M. (1978). Physiology and Biochemistry of Seeds in Relation to Germination, Vol. 1. Development, Germination, and Growth. Berlin: Springer-Verlag.

Bianciotto, V., Bandi, C., Minerdi, D., Sironi, M., Tichy, H. V., and Bonfante, P. (1996). An obligately endosymbiotic mycorrhizal fungus itself harbors obligately intracellular bacteria. Appl. Environ. Microbiol. 62, 3005-3010.

Bianciotto, V., Genre, A., Jargeat, P., Lumini, E., Bécard, G., and Bonfante, P. (2004). Vertical transmission of endobacteria in the arbuscular mycorrhizal fungus Gigaspora margarita through generation of vegetative spores. Appl. Environ. Microbiol. 70, 3600-3608. doi: 10.1128/AEM.70.6.3600-3608.2004

Bianciotto, V., Lumini, E., Bonfante, P., and Vandamme, P. (2003). 'Candidatus Glomeribacter gigasporarum' gen. nov., sp. nov., an endosymbiont of arbuscular mycorrhizal fungi. Int. J. Syst. Evol. Microbiol. 53, 121-124. doi: 10.1099/ijs.0.02382-0

Biondini, M. E., Bonham, C. D., and Redente, E. F. (1985). Secondary successional patterns in a sagebrush (Artemisia tridentata) community as they relate to soil disturbance and soil biological activity. Vegetatio 60, 25-36. doi: 10.1007/BF00053909

Blanchette, R. A. (1991). Delignification by wood-decay fungi. Annu. Rev. Phytopathol. 29, 381-398. doi: 10.1146/annurev.py.29.090191.002121

Blumenstein, K., Albrectsen, B. R., Martín, J. A., Hultberg, M., Sieber, T. N., Helander, M., et al. (2015a). Nutritional niche overlap potentiates the use of endophytes in biocontrol of a tree disease. Biocontrol 60, 655-667. doi: 10.1007/s10526-015-9668-1

Blumenstein, K., Macaya-Sanz, D., Martín, J. A., Albrectsen, B. R., and Witzell, J. (2015b). Phenotype MicroArrays as a complementary tool to next generation sequencing for characterization of tree endophytes. Front. Microbiol. 6:1033. doi: $10.3389 /$ fmicb.2015.01033

Bochner, B. R. (1989). Sleuthing out bacterial identities. Nature 339, 157-158. doi: $10.1038 / 339157 \mathrm{a} 0$

Bochner, B. R. (2003). New technologies to assess genotype-phenotype relationships. Nat. Rev. Genet. 4, 309-314. doi: 10.1038/nrg1046

Bochner, B. R. (2008). Global phenotypic characterization of bacteria. FEMS Microbiol. Rev. 33, 191-205. doi: 10.1111/j.1574-6976.2008.00149.x

Bochner, B. R., and Savageau, M. A. (1977). Generalized indicator plate for genetic, metabolic, and taxonomic studies with microorganisms. Appl. Environ. Microbiol. 33, 434-444.

Bochner, B. R., Gadzinksi, P., and Panomitros, E. (2001). Phenotype MicroArrays for high-throughput phenotypic testing and assay of gene function. Genome Res. 11, 1246-1255. doi: 10.1101/gr.186501

Buckeridge, M. S., dos Santos, H. P., and Tiné, M. A. S. (2000). Mobilisation of storage cell wall polysaccharides in seeds. Plant Physiol. Biochem. 38, 141-156. doi: 10.1016/S0981-9428(00)00162-5

Busby, P. E., Peay, K. G., and Newcombe, G. (2015). Common foliar fungi of Populus trichocarpa modify Melampsora rust disease severity. New Phytol. 209, 1681-1692. doi: 10.1111/nph.13742

Clarke, K. R. (1993). Non-parametric multivariate analyses of changes in community structure. Austral Ecol. 18, 117-143. doi: 10.1111/j.1442-9993.1993. tb00438.x

Clarke, K. R., and Green, R. H. (1988). Statistical design and analysis for a 'biological effects' study. Mar. Ecol. Prog. Ser. 46, 213-226. doi: 10.3354/meps046213

Coleman, J. J., Rounsley, S. D., Rodriguez-Carres, M., Kuo, A., Wasmann, C. C., Grimwood, J., et al. (2008). The genome of Nectria haematococca: contribution of supernumerary chromosomes to gene expansion. PLoS Genet. 5:e1000618. doi: 10.1371/journal.pgen.1000618

Covert, S. F. (1998). Supernumerary chromosomes in filamentous fungi. Curr. Genet. 33, 311-319. doi: 10.1007/s002940050342

Davison, J., Moora, M., Öpik, M., Adholeya, A., Ainsaar, L., Bâ, A., et al. (2015). Global assessment of arbuscular mycorrhizal fungus diversity reveals very low endemism. Science 349, 970-973. doi: 10.1126/science.aab1161
Del Rio, T. G., Abt, B., Spring, S., Lapidus, A., Nolan, M., Tice, H., et al. (2010). Complete genome sequence of Chitionphaga pinensis type strain (UQM $2034^{\mathrm{T}}$ ). Stand. Genomic Sci. 2, 87-95. doi: 10.4056/sigs.661199

Desirò, A., Faccio, A., Kaech, A., Bidartondo, M. I., and Bonfante, P. (2015). Endogone, one of the oldest plant-associated fungi, host unique Mollicutesrelated endobacteria. New Phytol. 205, 1464-1472. doi: 10.1111/nph.13136

Dobranic, J. K., and Zak, J. C. (1999). A microtiter plate procedure for evaluating fungal functional diversity. Mycologia 91, 756-765. doi: 10.2307/3761529

Druzhinina, I. S., Komon-Zelazowska, M., Atanasova, L., Seidl, V., and Kubicek, C. P. (2010). Evolution and ecophysiology of the industrial producer Hypocrea jecorina (Anamorph Trichoderma reesei) and a new sympatric agamospecies related to it. PLoS ONE 5:e9191. doi: 10.1371/journal.pone.0009191

Druzhinina, I. S., Schmoll, M., Seiboth, B., and Kubicek, C. P. (2006). Global carbon utilization profiles of wild-type, mutant, and transformant strains of Hypocrea jecorina. Appl. Environ. Microbiol. 72, 2126-2133. doi: 10.1128/AEM.72.3.2126-2133.2006

Estrada, C., Degner, E. C., Rojas, E. I., Wcislo, W. T., and Van Bael, S. A. (2015). The role of endophyte diversity in protecting plants from defoliation by leaf-cutting ants. Curr. Sci. 109, 55-61.

Ewing, B., and Green, P. (1998). Base-calling of automated sequencer traces using Phred. II. Error probabilities. Genome Res. 8, 186-194. doi: 10.1101/gr.8.3.186

Ewing, B., Hillier, L., Wendl, M. C., and Green, P. (1998). Base-calling of automated sequencer traces using Phred. I. Accuracy assessment. Genome Res. 8, 175-185. doi: 10.1101/gr.8.3.175

Frey-Klett, P., Garbaye, J., and Tarkka, M. (2007). The mycorrhiza helper bacteria revisited. New Phytol. 176, 22-36. doi: 10.1111/j.1469-8137.2007.02191.x

Friedl, M. A., Kubicek, C. P., and Druzhinina, I. S. (2008). Carbon source dependence and photostimulation of conidiation in Hypocrea atroviridis. Appl. Environ. Microbiol. 74, 245-250. doi: 10.1128/AEM.02068-07

Gale, G. R., Harrington, R. L., and Pate, A. F. (1960). The preparation of mycelial suspensions of dermatophytes for metabolic studies. J. Invest. Dermatol. 34, 167-169. doi: 10.1038/jid.1960.22

Gallery, R. E., Dalling, J. W., and Arnold, A. E. (2007). Diversity, host affinity, and distribution of seed-infecting fungi: a case study with Cecropia. Ecology 88, 582-588. doi: 10.1890/05-1207

Gallery, R. E., Moore, D. J. P., and Dalling, J. W. (2010). Interspecific variation in susceptibility to fungal pathogens in seeds of 10 tree species in the neotropical genus Cecropia. J. Ecol. 98, 147-155. doi: 10.1111/j.1365-2745.2009.01589.x

Ghignone, S., Salvioli, A., Anca, I.-A., Lumini, E., Ortu, G., Petiti, L., et al. (2012). The genome of the obligate endobacterium of an AM fungus reveals an interphylum network of nutritional interactions. ISME J. 6, 136-145. doi: 10.1038 /ismej. 2011.110

Gordon, T. R., and Leveau, J. H. J. (2010). Plant pathology: a story about biology. Annu. Rev. Phytopathol. 48, 293-309. doi: 10.1146/annurev-phyto080508-081919

Greetham, D. (2014). Phenotype microarray technology and its application in industrial biotechnology. Biotechnol. Lett. 36, 1153-1160. doi: 10.1007/s10529-014-1481-x

Grennan, A. K. (2007). The role of trehalose biosynthesis in plants. Plant Physiol. 144, 3-5. doi: 10.1104/pp.104.900223

Grimmer, M. K., Foulkes, M. J., and Paveley, N. D. (2012). Foliar pathogenesis and plant water relations: a review. J. Exp. Bot. 63, 4321-4331. doi: $10.1093 / \mathrm{jxb} / \mathrm{ers} 143$

Grizzle, H. W., and Zak, J. C. (2006). A microtiter plate procedure for evaluating fungal functional diversity on nitrogen substrates. Mycologia 98, 353-363. doi: $10.3852 /$ mycologia. 98.2 .353

Heilmann-Clausen, J., and Boddy, L. (2008). "Distribution patterns of wood-decay basidiomycetes at the landscape to global scale," in Ecology of Saprotrophic Basidiomycetes (British Mycological Society Symposia Series Volume 28), eds L. Boddy, J. C. Frankland, and P. van West (London: Academic Press), 3-372.

Henry, C., Bledsoe, S. W., Siekman, A., Kollman, A., Waters, B. M., Feil, R., et al. (2014). The trehalose pathway in maize: conservation and gene regulation in response to the diurnal cycle and extended darkness. J. Exp. Bot. 65, 5959-5973. doi: 10.1093/jxb/eru335

Herold, A., and Lewis, D. H. (1977). Mannose and green plants: occurrence, physiology and metabolism, and use as a tool to study the role of orthophosphate. New Phytol. 79, 1-40. doi: 10.1111/j.1469-8137.1977.tb02178.x 
Hobbie, E. A., Watrud, L. S., Maggard, S., Shiroyama, T., and Rygiewicz, P. T. (2003). Carbohydrate use and assimilation by litter and soil fungi assessed by carbon isotopes and BIOLOG ${ }^{\circledR}$ assays. Soil Biol. Biochem. 35, 303-311. doi: 10.1016/S0038-0717(02)00281-X

Hoffman, M. T., and Arnold, A. E. (2010). Diverse bacteria inhabit living hyphae of phylogenetically diverse fungal endophytes. Appl. Environ. Microbiol. 76, 4063-4075. doi: 10.1128/AEM.02928-09

Hoffman, M. T., Gunatilaka, M. K., Wijeratne, K., Gunatilaka, L., and Arnold, A. E. (2013). Endohyphal bacterium enhances production of indole-3-acetic acid by a foliar fungal endophyte. PLOS ONE 8:e73132. doi: 10.1371/journal.pone.0073132

Izumi, H., Anderson, I. C., Alexander, I. J., Killham, K., and Moore, E. R. B. (2005). Endobacteria in some ectomycorrhiza of Scotspine (Pinus sylvestris). FEMS Microbiol. Ecol. 56, 34-43. doi: 10.1111/j.1574-6941.2005. 00048.x

Jones, J. D. G., and Dangl, J. L. (2006). The plant immune system. Nature 444, 323-329. doi: $10.1038 /$ nature 05286

Kivlin, S. N., Hawkes, C. V., and Treseder, K. K. (2011). Global diversity and distribution of arbuscular mycorrhizal fungi. Soil Biol. Biogeochem. 43, 2294-2303. doi: 10.1016/j.soilbio.2011.07.012

Kosina, S. M., Schnebly, S. R., and Obendorf, R. L. (2013). Are Raffinose and Stachyose unloaded from soybean seed coats to developing embryos? Open Plant Sci. J. 7, 10-16. doi: 10.2174/1874294701307010010

Krieg, N. R., Staley, J. T., Brown, D. R., Hedlund, B. P., Paster, B. J., Ward, N. L., et al. (2010). "Volume Four: The Bacteroidetes, Spirochaetes, Tenericutes (Mollicutes), Acidobacteria, Fibrobacteres, Fusobacteria, Dictyoglomi, Gemmatimonadetes, Lentisphaerae, Verrucomicrobia, Chlamydiae, and Planctomycetes," in Bergey's Manual of Systematic Bacteriology 2nd Edn., eds M. Goodfellow, P. Kämpfer, J. Chun, P. De Vos, F. Rainey, and W. B. Whitman (New York, NY: Springer), 25-467.

Kubicek, C. P., Bissett, J., Druzhinina, I., Kullnig-Gradinger, C., and Szakacs, G. (2003). Genetic and metabolic diversity of Trichoderma: a case study on South-East Asian isolates. Fungal Genet. Biol. 38, 310-319. doi: 10.1016/S1087-1845(02)00583-2

Kuo, T. M., Doehlert, D. C., and Crawford, C. G. (1990). Sugar metabolism in germinating soybean seeds. Plant Physiol. 93, 1514-1520. doi: 10.1104/pp.93.4.1514

Lahuta, L. B., Górecki, R. J., Zalewski, K., and Hedley, C. L. (2007). Sorbitol accumulation during natural and accelerated ageing of pea (Pisum sativum L.) seeds. Acta Physiol. Plant 29, 527-534. doi: 10.1007/s11738-007-0063-0

Lane, D. J. (1991). "16S/23S rRNA sequencing," in Nucleic Acid Techniques in Bacterial Systematics, eds E. Stackebrandt and M. Goodfellow (Chichester: John Wiley and Sons), 115-175.

Lee, H. B., and Magan, N. (1999). Environmental factors and nutritional utilization patterns affect niche overlap indices between Aspergillus ochraceus and other spoilage fungi. Lett. Appl. Microbiol. 28, 300-304. doi: 10.1046/j.1365-2672.1999.00521.x

Leigh, E. G. Jr. (1999). Tropical Forest Ecology: A View from Barro Colorado Island. New York, NY: Oxford University Press.

Loewus, F. A., and Murthy, P. P. N. (2000). myo-Inositol metabolism in plants. Plant Sci. 150, 1-19. doi: 10.1016/S0168-9452(99)00150-8

Loudon, A. H., Holland, J. A., Umile, T. P., Burzynski, E. A., Minbiole, K. P. C., and Harris, R. N. (2014). Interactions between amphibians' symbiotic bacteria cause the production of emergent anti-fungal metabolites. Front. Microbiol. 5:441. doi: 10.3389/fmicb.2014.00441

Lumini, E., Bianciotto, V., Jargeat, P., Novero, M., Salvioli, A., Faccio, A., et al. (2007). Presymbiotic growth and sporal morphology are affected in the arbuscular mycorrhizal fungus Gigaspora margarita cured of its endobacteria. Cell. Microbiol. 9, 1716-1729. doi: 10.1111/j.1462-5822.2007. 00907.x

Lunn, J. E., Delorge, I., Figueroa, C. M., Van Dijck, P., and Stitt, M. (2014). Trehalose metabolism in plants. Plant, J. 79, 544-567. doi: 10.1111/tpj.12509

Maddison, D. R., and Maddison, W. P. (2005). ChromaSeq Module. Mesquite: A Modular System for Evolutionary Analysis. Version 1.06. Available online at: http://mesquiteproject.org/

Maddison, W. P., and Maddison, D. R. (2009). Mesquite: A Modular System for Evolutionary Analysis. Version 2.6. Available online at: http://mesquiteproject.org/
Márquez, L. M., Redman, R. S., Rodriguez, R. J., and Roossink, M. L. (2007). A virus in a fungus in a plant: three-way symbiosis required for thermal tolerance. Science 315, 513-515. doi: 10.1126/science.1136237

Mohr, K. I., Volz, C., Jansen, R., Wray, V., Hoffman, J., Bernecker, S., et al. (2015). Pinensins: the first antifungal lantibiotics. Angew. Chem. Int. Ed. 54, 11254-11258. doi: 10.1002/anie.201500927

Moran, N. A., Tran, P., and Gerardo, N. M. (2005). Symbiosis and insect diversification: an ancient symbiosis of sap-feeding insects from the bacterial phylum Bacteroidetes. Appl. Environ. Microbiol. 71, 8802-8810. doi: 10.1128/AEM.71.12.8802-8810.2005

Oksanen, J., Blanchet, F. G., Kindt, R., Legendre, P., Minchin, P. R., O’Hara, R. B., et al. (2016). vegan: Community Ecology Package. R Package Version 2.3-3. Available online at: http://CRAN.R-project.org/package $=$ vegan

Oliva, J., Stenlid, J., and Martínez-Vilalta, J. (2014). The effect of fungal pathogens on the water and carbon economy of trees: implications for drought-induced mortality. New Phytol. 203, 1028-1035. doi: 10.1111/nph.12857

Orbach, M. J., Chumley, F. G., and Valent, B. (1996). Electrophoretic karyotypes of Magnaporthe grisea pathogens of diverse grasses. Mol. Plant Microbe Interact. 9, 261-271. doi: 10.1094/MPMI-9-0261

Partida-Martínez, L. P., Groth, I., Schmitt, I., Richter, W., Roth, M., and Hertweck, C. (2007b). Burkholderia rhizoxinica sp. nov. and Burkholderia endofungorum sp. nov., bacterial endosymbionts of the plant-pathogenic fungus Rhizopus microsporus. Int. J. Syst. Evol. Microbiol. 57, 2583-2590. doi: $10.1099 /$ ijs.0.64660-0

Partida-Martínez, L. P., and Hertweck, C. (2005). Pathogenic fungus harbours endosymbiotic bacteria for toxin production. Nature 437, 884-888. doi: $10.1038 /$ nature 03997

Partida-Martínez, L. P., Monajembashi, S., Greulich, K.-O., and Hertweck, C. (2007a). Endosymbiont-dependent host reproduction maintains bacterialfungal mutualism. Curr. Biol. 17, 773-777. doi: 10.1016/j.cub.2007.03.039

Pegg, A. E., and Casero, R. A. Jr. (2011). Current status of the polyamine research field. Methods Mol. Biol. 720, 3-35. doi: 10.1007/978-1-61779-034-8_1

Pfliegler, W. P., Atanasova, L., Karanyicz, E., Sipiczki, M., Bond, U., Druzhinina, I. S., et al. (2014). Generation of new genotypic and phenotypic features in artificial and natural yeast hybrids. Food Technol. Biotechnol. 52, 46-57. doi: 10.1007/s00253-016-7481-0

Queiroz, R. J. B., and Cazetta, J. O. (2016). Proline and trehalose in maize seeds germinating under low osmotic potentials. Rev. Bras. Eng. Agríc. Ambient. 20, 22-28. doi: 10.1590/1807-1929/agriambi.v20n1p22-28

R Core Team (2015). R: A Language and Environment for Statistical Computing. Vienna: R Foundation for Statistical Computing. Available online at: http://www.R-project.org/

Redford, A. J., Bowers, R. M., Knight, R., Linhard, Y., and Fierer, N. (2010). The ecology of the phyllosphere: geographic and phylogenetic variability in the distribution of bacteria on tree leaves. Environ. Microbiol. 12, 2885-2893. doi: 10.1111/j.1462-2920.2010.02258.x

Rice, A. V., and Currah, R. S. (2005). Profiles from Biolog FF plates and morphological characteristics support recognition of Oidiodendron fimicola sp. nov. Stud. Mycol. 53, 75-82. doi: 10.3114/sim.53.1.75

Ruiz-Herrera, J., León-Ramírez, C., Vera-Nu-ez, A., Sánchez-Arreguín, A., RuizMedrano, R., Salgado-Lugo, H., et al. (2015). A novel intracellular nitrogenfixing symbiosis made by Ustilago maydis and Bacillus spp. New Phytol. 207, 769-777. doi: 10.1111/nph.13359

Salvioli, A., Chiapello, M., Fontaine, J., Hadj-Sahraoui, A. L., GrandmouginFerjani, A., Lanfranco, L., et al. (2010). Endobacteria affect the metabolic profile of their host Gigaspora margarita, an arbuscular mycorrhizal fungus. Environ. Microbiol. 12, 2083-2095. doi: 10.1111/j.1462-2920.2010.02246.x

Salvioli, A., Ghignone, S., Novero, M., Navazio, L., Venice, F., Bagnaresi, P., et al. (2016). Symbiosis with an endobacterium increases the fitness of a mycorrhizal fungus, raising its bioenergetic potential. ISME J. 10, 130-144. doi: 10.1038 /ismej.2015.91

Sangkhobol, V., and Skerman, V. B. D. (1981). Chitinophaga, a new genus of chitinolytic myxobacteria. Int. J. Syst. Bacteriol. 31, 285-293. doi: 10.1099/00207713-31-3-285

Sarmiento, C., Zalamea, P.-C., Dalling, J. W., Davis, A. S., and Arnold, A. E. (2015). "Seed-associated fungi: effects on seed survival and germination of tropical pioneer species," in Conference for the Association for Tropical Biology and Conservation, July 12-16 (Honolulu, HI). 
Sato, Y., Narisawa, K., Tsuruta, K., Umezu, M., Nishizawa, T., Tanaka, K., et al. (2010). Detection of Betaproteobacteria inside the mycelium of the fungus Mortierella elongata. Microbes Environ. 25, 321-324. doi: 10.1264/jsme2.ME10134

Savatin, D. V., Gramegna, G., Modesti, V., and Cervone, F. (2014). Wounding in the plant tissue: the defense of a dangerous passage. Front. Plant Sci. 5:470. doi: 10.3389/fpls.2014.00470

Schädel, C., Blöchl, A., Richter, A., and Hoch, G. (2009). Short-term dynamics of nonstructural carbohydrates and hemicelluloses in young branches of temperate forest trees during bud break. Tree Physiol. 29, 901-911. doi: 10.1093/treephys/tpp034

Schafer, M., and Kotanen, P. M. (2003). The influence of soil moisture on losses of buried seeds to fungi. Acta Oecol. 24, 255-263. doi: 10.1016/j.actao.2003.09.001

Schneider, C. A., Rasband, W. S., and Eliceiri, K. W. (2012). NIH to ImageJ: 25 years of image analysis. Nat. Methods 9, 671-675. doi: 10.1038/ nmeth.2089

Shaffer, J. (2017). Justinshaffer/Endohyphal_Bacterium_Alters_Substrate_Use_by_ Fusarium_Keratoplasticum: Second Release of Code for Analyzing Biolog FF Microplate Data [Data Set]. Zenodo. doi: 10.5281/zenodo. 250931

Shaffer, J. P., Sarmiento, C., Zalamea, P.-C., Gallery, R. E., Davis, A. S., Baltrus, D. A., et al. (2016). Diversity, specificity, and phylogenetic relationships of endohyphal bacteria in fungi that inhabit tropical seeds and leaves. Front. Ecol. Evol. 4:116. doi: 10.3389/fevo.2016.00116

Sharma, M., Schmid, M., Rothballer, M., Hause, G., Zucarro, A., Imanl, J., et al. (2008). Detection and identification of bacteria intimately associated with fungi in the order Sebacinales. Cell. Microbiol. 10, 2235-2246. doi: 10.1111/j.1462-5822.2008.01202.x

Short, D. P. G., O’Donnell, K., Thrane, U., Nielson, K. F., Zhang, N., Juba, J. H., et al. (2013). Phylogenetic relationships among members of the Fusarium solani species complex in human infections and the descriptions of F. keratoplasticum sp. nov. and F. petroliphilum stat. nov. Fungal Genet. Biol. 53, 59-70. doi: 10.1016/j.fgb.2013.01.004

Singh, M. P. (2009). Application of Biolog FF MicroPlate for substrate utilization and metabolite profiling of closely related fungi. J. Microbiol. Methods 77, 102-108. doi: 10.1016/j.mimet.2009.01.014

Spraker, J. E., Sanchez, L. M., Lowe, T. M., Dorrestein, P. C., and Keller, N. P. (2016). Ralstonia solanacearum lipopeptide induces chlamydospore development in fungi and facilitates bacterial entry into fungal tissues. ISME J. 10, 2317-2330. doi: 10.1038/ismej.2016.32

Tanzer, M. M., Arst, H. N., Skalchunes, A. R., Coffin, M., Darveaux, B. A., Heiniger, R. W., et al. (2003). Global nutritional profiling for mutant and chemical modeof-action analysis in filamentous fungi. Funct. Integr. Genomics 3, 160-170. doi: $10.1007 /$ s10142-003-0089-3
Tedersoo, L., Bahram, M., Põlme, S., Kõljalg, U., Yorou, N. S., Wijesundera, R., et al. (2014). Global diversity and geography of soil fungi. Science 346:1256688. doi: $10.1126 /$ science. 1256688

Thomas, F., Hehemann, J.-H., Rebuffet, E., Czjzek, M., and Michel, G. (2011). Environmental and gut Bacteroidetes: the food connection. Front. Microbiol. 2:93. doi: $10.3389 /$ fmicb. 2011.00093

U'Ren, J. (2016). DNA Extraction from Fungal Mycelium using Extract-n-Amp. Available online at: www.protocols.io

U'Ren, J. M., Dalling, J. W., Gallery, R. E., Maddison, D. R., Davis, E. C., Gibson, C. M., et al. (2009). Diversity and evolutionary origins of fungi associated with seeds of a neotropical pioneer tree: a case study for analyzing fungal environmental samples. Mycol. Res. 113, 432-449. doi: 10.1016/j.mycres.2008.11.015

U’Ren, J. M., Miadlikowska, J., Zimmerman, N. B., Lutzoni, F., Stajich, J. E., and Arnold, A. E. (2016). Contributions of North American endophytes to the phylogeny, ecology, and taxonomy of Xylariaceae (Sordariomycetes, Ascomycota). Mol. Phylogenet. Evol. 98, 210-232. doi: 10.1016/j.ympev.2016.02.010

van der Heijden, M. G. A., Martin, F. M., Selosse, M.-A., and Sanders, I. R. (2015). Mycorrhizal ecology and evolution: the past, the present, and the future. New Phytol. 205, 1406-1423. doi: 10.1111/nph.13288

Vannini, C., Carpentieri, A., Salvioli, A., Novero, M., Marsoni, M., Testa, L., et al. (2016). An interdomain network: the endobacterium of a mycorrhizal fungus promotes antioxidative responses in both fungal and plant hosts. New Phytol. 211, 265-275. doi: 10.1111/nph.13895

Waller, F., Achatz, B., Baltruschat, H., Fodor, J., Becker, K., Fischer, M., et al. (2005). The endophytic fungus Piriformospora indica reprograms barley to salt-stress tolerance, disease resistance, and higher yield. Proc. Natl. Acad. Sci. U.S.A. 102, 13386-13391. doi: 10.1073/pnas.0504423102

Zalamea, P.-C., Sarmiento, C., Arnold, A. E., Davis, A. S., and Dalling, J. W. (2015). Do soil microbes and abrasion by soil particles influence persistence and loss of physical dormancy in seeds of tropical pioneers? Front. Plant Sci. 5:799. doi: $10.3389 /$ fpls.2014.00799

Conflict of Interest Statement: The authors declare that the research was conducted in the absence of any commercial or financial relationships that could be construed as a potential conflict of interest.

Copyright (C) 2017 Shaffer, U'Ren, Gallery, Baltrus and Arnold. This is an open-access article distributed under the terms of the Creative Commons Attribution License (CC $B Y)$. The use, distribution or reproduction in other forums is permitted, provided the original author(s) or licensor are credited and that the original publication in this journal is cited, in accordance with accepted academic practice. No use, distribution or reproduction is permitted which does not comply with these terms. 